\title{
LA INTANGIBILIDAD COMPETENCIAL DE LOS DERECHOS FUNDAMENTALES. FORMA DE ESTADO Y DERECHOS FUNDAMENTALES ${ }^{1}$
}

\author{
IGNACIO VILLAVERDE MENÉNDEZ \\ Profesor Titular de de Derecho Constitucional \\ Universidad de Oviedo
}

\section{SUMARIO}

I. Derechos fundamentales y forma de Estado. El planteamiento de problema.

II. La garantía de la unidad del Estado a través de los derechos fundamentales.

III. Derechos fundamentales y reparto competencial.

IV. ¿Pueden los Estatutos de Autonomía tener su propia declaración de derechos?

\section{DERECHOS FUNDAMENTALES Y FORMA DE ESTADO. EL PLANTEAMIENTO DEL PROBLEMA}

La percepción de las cuestiones relativas a la forma de Estado ha estado tradicionalmente ligada a lo territorial. Si la forma de Estado es el modo en que se distribuye territorialmente el poder público, parece inevitable abordar la organización territorial del Estado, en cuanto estructura orgánico-funcional que articula aquella distribución, desde una perspectiva estrictamente espacial. No cabe duda de que es una cuestión de quién y para qué partes de ese territorio ese quién puede hacer normas²; pero no sólo.

1 El presente trabajo forma parte de un proyecto más ambicioso en el que se trata de estudiar el impacto de las formas de Estado descentralizadas en el sistema de derechos fundamentales y la garantía de la igualdad en la diversidad propia de aquéllas.

2 Esta percepción es fácilmente deducible de la lectura de los clásicos en la materia. Valga ahora la cita de K.C. WHEARE, Federal Government, Oxford University Press, London/New Cork/Toronto, 1963. En cierto modo este es el enfoque frente al que se pronuncia Akhil Reed, AMAR, The Bill of Rights. Creation and Reconstruction, Yale University Press, New Haven/London, 
El autogobierno descentralizado promueve la diversidad, y así es querido por las Constituciones que crean Estados compuestos. Pero esa diversidad puede socavar el pilar fundamental del Estado democrático de Derecho: el estatus básico de libertad e igualdad de todos los ciudadanos, residan donde re$\operatorname{sidan}^{3}$. El hipotético, y en ocasiones real, conflicto entre la necesidad democrática de garantizar ese estatus básico de ciudadano libre e igual en todo el Estado y la diversidad derivada de la descentralización política no pueden resolverse acudiendo únicamente a los criterios de articulación territorial del poder político. Deben establecerse instrumentos que aseguren que la descentralización del poder político no amenaza la posición constitucional del ciudadano en el Estado democrático; esta pudiere ser la función de la reserva del art. 81.1 CE y de la habilitación competencial del art. 149.1.1 CE.

No se quiere decir con ello que entre ambos principios estructurales de la Constitución, también de la española, el democrático y el descentralizador, medie un remedo de jerarquización en la que éste se somete al otro. Se trata más bien de su conjugación sistemática en el marco de una Constitución democrática (principio de unidad constitucional ${ }^{4}$ ) de forma que haya una integración recíproca entre la indispensable garantía del estatus básico de ciudadano libre e igual para la existencia del Estado democrático de Derecho y la organización territorial del Estado.

Repárese, además, en que uno de los argumentos en la defensa del Estado compuesto, como es de sobra conocido, ha sido justamente su mayor idoneidad para la realización de una democracia avanzada y moderna ${ }^{5}$. Pero la democracia no es posible, como también es sabido, sin la garantía de un estatus de libertad e igualdad básica del ciudadano.

\section{A) El estatus básico de Ciudadano libre e igual como Parte INDISPENSABLE DE LA CONSTITUCIÓN DEMOCRÁTICA}

El sistema democrático requiere de una Constitución concebida como norma jurídica suprema, pues sólo así cabe distinguir la voluntad soberana del

1998. Este autor, en este libro, trata justamente de subrayar la importancia que tuvo la confección de la Declaración de Derechos de la Constitución norteamericana mediante la aprobación de sus conocidas Enmiendas también para el modo de articular las relaciones entre Federación y Estados federados (véase la introducción y el primer epígrafe de su primer capítulo). Su tesis es que las Enmiendas introdujeron un elenco de derechos constitucionales de todos los norteamericanos que la Federación debía amparar frente a los Estado federados. La otra gran aportación a este debate la ofreció Richard STEWART, Federalism and Rights. Federalism: Allocating Responsability between the Federal and States Courts, Georgia Law Review, núm.19, 1985, p. 917 y ss.

3 Véase passim Hans KELSEN, Esencia y valor de la democracia, Guadarrama, Barcelona, 1977 y Albert BLECKMANN, Vom Sinn und Zweck des Demokratieprinzips. Ein Beitrag zur teleologischen Auslegung des Staatsorganisationsrechts, Duncker \& Humblot, Berlin, 1998, passim.

4 Sobre este principio y sus exigencias es un clásico el libro de Friedrich MÜLLER, Die Einhait der Verfassung. Elemente einer Verfassungstheorie III, Duncker \& Humblot, Berlin, 1984.

5 Sobre este particular véase A.E. Dick HOWARD, The Values of Federalism, New European Law Review, núm. 1, 1993, p. 143 y ss.; Geoffrey SAWER, Modern Federalism, Pitman Australia, Victoria, 1976 (2. ${ }^{\mathrm{a}}$ edic., rev.), Caps. 1,8 y 11; 
Pueblo, que se expresa en el ejercicio del poder constituyente (la Constitución), de la voluntad de los ciudadanos, que en cambio lo hace a través del ejercicio de los poderes constituidos (en particular, la ley) ${ }^{6}$. Y así debe ser porque este es el único modo (hasta la actualidad) de asegurar la libertad e igualdad natural de todo hombre antes del pacto social. De ahí que el Estado para ser democrático debe juridificarse (Estado de Derecho) para así servir de forma óptima a la garantía, indisponible a los poderes constituidos, de las expectativas de autodisposición de la propia conducta de los individuos (libertad) y de la igualdad de todos en la realización de dichas expectativas y en la posición de cada uno frente al ordenamiento jurídico (igualdad formal). Sólo si el ordenamiento jurídico (el Estado) asegura esa condición de persona libre e igual de forma que ningún poder constituido pueda negarla (razón por la que la garantía de esa libertad e igualdad debe efectuarse en la Constitución) el sujeto a ese ordenamiento deja de ser un simple súbdito para convertirse en ciudadano ${ }^{7}$.

En esto consiste el estatus básico de ciudadano libre e igual, en la titularidad y disposición por la persona sobre ciertas expectativas constitucionalmente garantizadas de autodeterminación de la propia conducta, y en la

6 Consúltense, además de los ya citados de H. KELSEN y A. BLECKMANN en la nota 3, los trabajos de Ernst Wolfgang BÖCKENFÖRDE Demokratie als Verfassungsprinzip, en "Staat, verfassung, Demokratie. Studien zur Verfassungstheorie und Verfassungsgeschichte", p. 289 y ss., Suhrkamp, Frankfurt, 1991; Konrad HESSE, Die normative Kraft der Verfassungsgesetzes, en "Verfassung. Beiträge zur Verfassungstheorie», Wissenschaftliche Buchgesellschaft, Darmstadt, 1978, p. 77 y ss.; de Martin KRIELE Das demokratische Prinzip, Veröffentlichungen der Vereinigung der Deutschen Staatsrechtslehrer, Hf. 29, 1971, p. 46 y ss., y su señero Einführung in die Staatslebere. Die gesechtlichen Legimitätsgrundlagen des demokratischen Verfassungsstaates, Rowolth, Hamburg, 1975; Jürgen HABERMAS, Facticidad y validez, Trotta, Madrid, 1998, p. 6, 22 y ss., pp. 363 y ss.; Ignacio de OTTO Y PARDO, Derecho Constitucional. Sistema de fuentes, Ariel, Barcelona, 1995, y Francisco BASTIDA, Constitución, soberanía, democracia, Revista del Centro de Estudios Constitucionales, núm. 8, 19991, p. 9 y ss. Francisco BASTIDA en su trabajo La soberanía borrosa: la democracia, Fundamentos, núm.1, 1998, p. 381 y ss., en particular p. 402 y ss., donde apelando a las categoría luhmniana de la autorreferencialidad ofrece argumentos capitales para pensar la sustancial correlación entre Constitución, democracia y derechos fundamentales.

7 Téngase en cuenta que aquí persona y ciudadano son dos nociones que deben subsumirse en una en el Estado democrático. El ciudadano es ante todo una persona, y toda persona debe ser reconocida como un ciudadano en potencia o en acto. Son de cita obligada aquí Benito ALÁEZ CORRAL, Nacionalidad, ciudadanía y democracia: ¿a quién pertenece la Constitución?, Centro de Estudios Políticos y Constitucionales, Madrid, 2006, passim, y en especial ppp. 195 y ss.; y algunas de las ideas de estas líneas tienen su fuente en el libro de T. Alexander ALEINIKOFF, Semblantes of Sovereignty. The Constitution, The State, and the American Citizenship, Harvard University Press, Massachussets/London, 2002, sobre todo Cap. 7 y 8 . Véase el libro de Hans H KLEIN, Hans, Die Grundrechte in demokratische Staat. Kritische Bemerkungen zur Aulegung der Grundrechte in der deutschen Staatsrechtslebre der Gegenwart, Kohlhammer, Stuttgart/Berlin/Mainz, 1974 (1. ${ }^{a}$ reimp), passim.Vale la pena recordar que esta es una condición de la Constitución democrática, no lo es de la Constitución como norma jurídica suprema ni de la Constitución del Estado compuesto. Ignacio de OTTO Y PARDO reparaba justamente en el hecho de que la Constitución del II Reich alemán no conocía ningún estatus jurídico constitucional unitario del ciudadano y sin embargo era un Estado federal (Estudios sobre Derecho estatal y autonómico, Civitas, Madrid, 1986, p. 161). 
igualdad en esa posición jurídica y en la sujeción a las normas que se crean en ese ordenamiento. Los derechos fundamentales no son sino las normas que expresan esa garantía de libertad e igualdad prohibiendo el uso del poder público tanto en el ámbito de realización de aquellas expectativas cuanto para crear desigualdades en ese estatus. Los derechos fundamentales neutralizan la omnipotencia del Soberano, nacional o popular, porque constitucionalizan en su núcleo un "fragmento de soberanía" 8 .

El sistema jurídico democrático está al servicio de la libertad e igualdad de los individuos y para alcanzar ese propósito organiza y pone a su servicio los procedimientos de creación y aplicación de normas; es decir, regula el uso del poder público (el recurso a la coacción para compeler conductas) ${ }^{9}$. Luego una de las funciones jurídicas esenciales de la Constitución democrática es la garantía de ese estatus básico de libertad e igualdad del ciudadano, porque sólo así el Estado que funda será un verdadero Estado democrático de Derecho. Y la forma de cumplir esa función ha sido incorporando a la Constitución la declaración de derechos fundamentales que definen la posición del individuo en los procesos de creación y aplicación de normas en ese ordenamiento jurídi$\mathrm{co}$, estructurados de forma tal que el ciudadano pueda intervenir en ellos, directa o indirectamente, en su condición de individuo libre e igual.

Así lo expresó la STC 25/1981 en su FJ 5 (a la que volveremos más abajo) al afirmar: "En el segundo aspecto, en cuanto elemento fundamental de un ordenamiento objetivo, los derechos fundamentales dan sus contenidos básicos a dicho ordenamiento, en nuestro caso al del Estado social y democrático de Derecho, y atañen al conjunto estatal. En esta función, los derechos fundamentales no están afectados por la estructura federal, regional o autonómica del Estado. Puede decirse que los derechos fundamentales, por cuanto fundan un status jurídico-constitucional unitario para todos los españoles y son decisivos en igual medida para la configuración del orden democrático en el Estado central y en las Comunidades Autónomas, son elemento unificador, tanto más cuanto el cometido de asegurar esta unificación, según el art. 155 de la Constitución, compete al Estado. Los derechos fundamentales son así un patrimonio común de los ciudadanos individual y colectivamente, constitutivos del ordenamiento jurídico cuya vigencia a todos atañe por igual. Establecen por así decirlo una vinculación directa entre los individuos y el Estado y actúan como fundamento de la unidad política sin mediación alguna" (reiterada luego en el FJ 14 de la STC 290/2000).

A través de los derechos fundamentales la Constitución democrática sustrae la realización de ciertas expectativas de autodisposición individual al

8 Esta sugestiva idea está en la obra citada de Francisco BASTIDA, La soberanía borrosa..., en particular su p. 427 y ss. También en BASTIDA, VILLAVERDE, REQUEJO, PRESNO, ALÁEZ, FERNÁDEZ, Teoría general de los derechos fundamentales en la Constitución de 1978, Tecnos, Madrid, 2004, pp. 37 y 38.

9 Veáse BASTIDA, VILLAVERDE, REQUEJO, PRESNO, ALÁEZ, FERNÁDEZ, Teoría general, ob.cit., p. 38 y ss.; en general Nicola MATEUCCI, Organización del poder y libertad, Trotta, Madrid, 1998. 
poder público, de ahí su condición de expectativas libres (fragmentos de soberanía individual). Una sustracción al ejercicio del poder público (de ahí su indisponibilidad) de la que todos los individuos son titulares sin que ninguna condición personal deba, en principio, alterar su estatus constitucional ${ }^{10}$. Tampoco su lugar de residencia o procedencia. El territorio no puede ser criterio de diferenciación. De esto nos ocuparemos más adelante.

La dignidad de la persona, que el art. 10.1 CE menciona, se sustancia en ese estatus que, como ese mismo precepto señala, es el fundamento del "orden político y de la paz social ${ }^{11}$. El respeto a esa dignidad introduce un principio de uniformidad en el trato del ciudadano en todo el territorio del Estado. Y es en este sentido que debe dársele al tan criticado FJ 5 de la STC 25/1981 que se ha transcrito previamente ${ }^{12}$. La afirmación de que la columna vertebral del Estado constitucional democrático de Derecho es la dignidad del ciudadano, concebida esta como el estatus básico de libertad e igualdad que condiciona el ejercicio del poder público en todo el territorio del Estado tiene capitales consecuencias para la estructura constitucional del Estado compuesto $^{13}$.

\section{B) Derechos Fundamentales y terRitorio}

Los derechos fundamentales condicionan y programan la estructura constitucional del Estado, su organización como Estado social y democrático de Derecho. Una predeterminación que alcanza también a la forma de Estado,

10 Claro está que la Constitución puede establecer diferencias entre sujetos titulares de derechos; y así lo hace la $\mathrm{CE}$ al distinguir entre españoles y extranjeros. Pero no es menos claro que el carácter democrático de un sistema es cuestión de grado y cuanto menor sea la diferenciación entre titulares de los derechos, más democrático es el sistema jurídico. Sobre esto, algo ya dice Francisco BASTIDA en su La soberanía borrosa, p. 411 y ss. Son de sumo interés las reflexiones de Benito ALÁEZ CORRAL en su artículo Nacionalidad y ciudadanía desde la perspectiva de la soberanía democrática, en "Extranjería e inmigración: aspectos jurídicos y socioeconómicos", Presno (Coord.), Tirant lo Blanch, Valencia, 2004, p. 43 y ss. También Peter HÄBERLE, Jürgen HABERMAS, Facticidad..., p. 620 y ss.; GOZZI, Cittadinanza e democracia. Elemento per una teoria costituzionale della democraczia comtemporanea, en "Democracia, diritti, costituzione", GOZZI (a cura),Il Mulino, Bologna, 1997, p. 199 y ss.

11 Véase Francisco BASTIDA, La soberania borrosa, ob.cit. p. 416 y ss.

12 Ejemplo de esa crítica es el comentario negativo que le merece a Miguel Angel CABELLOS ESPIÉRREZ en la p. 9 de su libro Distribución competencial, derechos de los ciudadanos e incidencia del derecho comunitario, Centro de Estudios Políticos y Constitucionales, Madrid, 2001.

13 Una vez más consúltense las reflexiones de Francisco BASTIDA FREIJEDO, La soberanía borrosa, ob.cit. p. 411 y ss.; también Peter HÄBERLE en su I diritti fondamentali nelle società pluraliste e la Costituzione del pluralismo, en "La democrazia alla fine del secolo", Luciani (a cura), Laterza, 1995, p. 102 y 103. No puede dejar de citarse el clásico de Ingo von MÜNCH, La dignidad del hombre en el derecho Constitucional, Revista Española de Derecho Constitucional, núm. 5, 1982, p. 9 y ss.; y el muy sugestivo de Meter HÄBERLE, Die Menschwürde als Grundlage der staatlichen Gemeinschaft, en "Handbuch des Staatsrechts" Bd. I, p. 815 y ss., Isensee/Kirchhof, C.F. Müller, Heidelberg, 1987. 
esto es, a la distribución territorial del poder político ${ }^{14}$. En el caso español tal programación de la forma de Estado por los derechos fundamentales se efectúa a través de los arts. 81, 139 y 149.1.1CE. Y no es casual que la forma de hacerlo haya sido mediante la garantía de la igualdad territorial en el art. 139 CE y con dos normas habilitantes, los arts. 81 y 149.1.1 CE, que fijan la forma y el alcance del procedimiento de creación de normas por los poderes públicos, centrales y periféricos, con las que desarrollar en el ordenamiento infraconstitucional el programa normativo contenido en los derechos fundamentales ${ }^{15}$.

Pero mientras que la garantía del estatus jurídico básico de libertad e igualdad del ciudadano es una necesidad jurídica para el Estado democrático de Derecho, no lo es, sin embargo, que su organización territorial deba ser descentralizada. La Constitución democrática puede fundar un Estado unitario sin que pierda por ello su carácter detal. Que la descentralización territorial es una forma más acabada de democracia es un postulado político, pero no una necesidad jurídica derivada del principio democrático.

Ahora bien, no es menos cierto que el sistema democrático se alza sobre el respeto a la diversidad. Tal cosa jurídicamente se deduce sin dificultad de la propia apertura estructural de las normas iusfundamentales. Como tales, estabilizan expectativas de autodeterminación de la conducta individual que permiten al ciudadano optar por una variedad de comportamientos posibles (incluso cuando el objeto del derecho fundamental es una prohibición de poder público y no la protección de un agere licere, caso del derecho a la inviolabilidad del domicilio, por ejemplo). No en vano de Otto afirmó que los derechos fundamentales son garantías de lo posible, y en esa posibilidad se realiza ya la diversidad. El sistema democrático requiere de una Constitución abierta, y si es así la diversidad es inevitable.

Esa diversidad puede verse incrementada si además de la apertura constitucional palpitante en los derechos fundamentales, y en la propia legitimidad democrática de la ley, se suma la diversidad territorial derivada de una organización territorial descentralizada. Diversidad territorial que alcanza sus cotas más intensas y extensas cuando la descentralización se realiza en el nivel de la ley; es decir, cuando la descentralización es política y no sólo una forma de autarquía o de desconcentración administrativa. Si así es, la diversidad territorial creada ahora por la disposición que los territorios autónomos tienen sobre la forma jurídica ley sólo puede hallar sus límites en la Constitución como norma suprema que es (supremacía definida justamente por su supe-

14 BASTIDA, VILLAVERDE, REQUEJO, PRESNO, ALÁEZ, FERNÁDEZ, Teoría general, ob.cit., p. 39 .

15 Sobre esta cuestión resultan indispensables las obras de Friedrich MÜLLER, Die positivität der Grundrechte. Fragen einer praktischen Grundrechtsdogmatik, Duncker \& Humblot, Berlin, 1980; Normstruktur und Normtivität, Duncker \& Humblot, Berlin, 1966 y de Ernst-Wolfgang BÖCKENFÖRDE, Schutzbereich, Eingriff, Verfassungsimmanente Schranken. Zur Kritik gegenwärtige Grundrechtsdogmatik, Der Staat, Hf. 2, Bd. 42., 2003, pp. 165 y ss. 
rioridad jerárquica sobre la ley, sea ésta creada por el Estado central, sea creada por los entes autónomos territoriales) ${ }^{16}$.

A ello debe añadirse, por lo demás, que las Constituciones habilitan a la ley, como es el caso español con los arts. 811 y $53.1 \mathrm{CE}$, para modular en ciertos casos el derecho fundamental mediante la fijación de sus límites o la regulación de su forma de realizarse en las relaciones jurídicas entre los poderes públicos y los individuos, y las de estos entre sí. En los Estados descentralizados, la ley de los territorios autónomos puede ejercer esas funciones y aumentar de este modo la diversidad de regímenes jurídicos de los derechos fundamentales en su inserción en la legalidad ordinaria.

Pero la diversidad, también la territorial, no puede ser obstáculo para la igualdad formal que reclama el estatus básico del ciudadano en el Estado constitucional democrático de Derecho ${ }^{17}$. La constitucionalmente lícita diversidad territorial encuentra su límite infranqueable en la igualdad de todos en la titularidad del estatus de ciudadano. De lo contrario, un principio contingente para el principio democrático (la descentralización territorial de la disposición sobre la ley) vaciaría justo aquel que resulta ser necesario para su existencia ${ }^{18}$.

La procedencia o la residencia del ciudadano, su ubicación territorial en definitiva, es una condición personal cuyo uso como criterio de diferenciación es prohibido por la Constitución democrática. En el caso español la ubicación territorial del ciudadano sería una "condición o circunstancia personal o social" que el art. $14 \mathrm{CE}$ interdicta como criterio de diferenciación entre españoles. Prohibición que encuentra su expresión, y su extensión más allá del estatus iusfundamental de ciudadano, en el art. 139 CE dentro del Título VIII: "Todos los españoles tienen los mismos derechos y obligaciones en cualquier parte del territorio del Estado".

Estructuralmente, en la Constitución democrática, la diversidad territorial encuentra su límite infranqueable en los derechos fundamentales, garantía del

16 Sobre esto véase Ignacio de OTTO Y PARDO, Derecho Constitucional, ob.cit., p. 247 y ss. Esa afirmación de la supremacía de la Constitución sobre los ordenamientos estatal y autonómicos es recogida sin paliativo por la jurisprudencia del TC, así SSTC 32/1981, FJ 5, 18/1982, FJ 1 o 35/1982 FJ 2. Es Ignacio de OTTO Y PARDO quien nos enseñó que el fundamento del principio autonómico y el carácter de la descentralización en el sistema constitucional español estriba en la disposición sobre la ley de los entes autónomos, Escritos sobre Derecho estatal y autonómico, Civitas, Madrid, 1986, primer capítulo, en especial la p. 41. No cabe duda de que esta tesis tiene una clara raigambre kelseniana, pues el autriaco ha insistido siempre en que la descentralización verdadera es la que se efectúa ya en el nivel de la ley, es decir, en el escalón normativo que sucede inmediatamente a la Constitución, Allgemeine Staatslehre, Max Gehlen, Bad Homburg/Berlin/Zürich, 1966 (reimp. 1. ${ }^{a}$ edic), pp. 166 y ss. En este mismo sentido se pronuncia Hans NAWIASKY, Allgemeine Staatslehere, Dritter Teil. Staatsrechtslehre, Verlagsanstalt Benziger \& Co. AG., Einsiedeln/Zürich/Köln, 1956, p. 151.

17 Francisco BASTIDA FREIJEDO, La soberanía borrosa, ob.cit., p. 417.

18 El principio dispositivo recogido en el art. 2 en relación con el Título VIII CE, es una buena prueba de la contingencia de la descentralización política en un Estado democrático de Derecho. 
estatus básico de libertad e igualdad del ciudadano. La Constitución que no obrase así dejaría de ser democrática y, en realidad, se reduciría a ser la norma fundante de un sistema confederal de Estados. Pero de ningún modo sería la norma constitutiva de un Estado compuesto y democrático de Derecho.

La dignidad del ciudadano, estribada en su estatus básico de libertad e igualdad, se ve amenazada, sobre todo en su dimensión igualitaria (todos gozan del mismo estatus en todo el territorio) con la diversidad derivada de la distribución territorial de la disposición sobre la ley.

\section{C) Los Derechos Fundamentales COMO PARTE DE LA GESAMTVERFASSung}

Es bien sabido que de la lógica jurídica de la estructura del Estado compuesto regido por el principio federal se deriva la necesidad de una Constitución global, de una Gesamtverfassung que funda el Gesamtstaat como orden jurídico total resultante de la suma de los ordenamientos territoriales parciales (central y periférico), y el ordenamiento superior a estos que establece justamente su existencia y el orden de reparto de competencias entre ellos. Es esa Constitución global la única que posee la competencia sobre las competencias (el poder de reforma constitucional que puede disponer del reparto de competencias entre centro y periferia) y capaz de reconducir a unidad los ordenamientos territoriales y el del Estado central por cuanto es ella la norma de imputación final de la validez de las restantes normas y actos de ese Totalordnung. La Constitución global encarna jurídicamente al Pueblo soberano ${ }^{19}$, dotando de unidad al Estado compuesto y elevándolo a la categoría de Gesamtstaat ${ }^{20}$.

En la Gesamtverfassung se establecen los ámbitos de autodeterminación de la conducta individual (o colectiva en su caso) indisponibles a los ordenamientos parciales. Esos ámbitos de autodisposición individual de la con-

19 WHEARE señala que una de las instituciones esenciales del "federal government" es la Constitución, concebida ésta como norma jurídica suprema, y preferiblemente escrita, al menos en lo relativo al establecimiento de un poder central y otros territoriales y a cómo se distribuyen entre ellos las competencias (Federal Government, ob.cit. p. 53 y ss.). Parece a todas luces que esa Constitución cumple las funciones de la Constitución global kelseniana; aunque es cierto que KELSEN le da un significado a la Gesamtverfassung casi tan metafísico como el de la Grundnorm. Así en su Allgemeine Staatslebre, ob.cit., p. 164 y 165, pp. 168, 171 y ss., 180, 193, y 198 y ss. Conviene recordar cómo KELSEN demostró que el hecho de que el Estado central tenga atribuida el poder de reforma de la Constitución federal (es decir la Constitución global) no autoriza a identificarlo como órgano de la Constitución global o que su norma materialmente constitucional resulte ser la Gesamtverfassung (p. 200, 208 y 221). KELSEN vuelve sobre esta teoría de la Gesamtverfassung en su La Giustizia costituzionale, Giuffrè, Milano, 1981, p. 79 y ss.

20 Véase la obra de Hans NAWIASKY, Allgemeine Staatslehere, ob.cit. p. 159 y ss., en especial p. 161. Paloma REQUEJO advierte de la diferencia formal que debe establecerse entre la Constitución total de los Estado federales y la CE, pero subraya su "identidad funcional-material"; véase su Bloque constitucional y bloque de la constitucionalidad, Universidad de Oviedo, Oviedo, 1997, pp. 50 y 51. 
ducta son ajenos al reparto de competencias porque en ella, en la Gesamtverfassung, ha expresado su voluntad normativa el Pueblo soberano con el propósito, si de una Constitución democrática se trata, de preservar el estatus de libertad e igualdad del ciudadano frente a los poderes constituidos.

Así pues, ni el Estado central puede esgrimir una competencia exclusiva sobre los derechos fundamentales, pues no son parte de su norma constitutiva. Ni los territorios pueden hacer lo propio. Dicho esto sin perjuicio de que sus normas constitutivas puedan tener su propia declaración de derechos fundamentales, que en cualquier caso no podrá contrariar lo dispuesto en la Gesamtverfassung.

La función que desempeña la Gesamtverfassung en el Estado democrático de Derecho descentralizado es la de, justamente, reconducir a unidad la diversidad territorial para asegurar los elementos esenciales y decisivos del principio democrático y el principio federal21: el estatus básico de igualdad y libertad de los ciudadanos y su participación directa o indirecta en los procesos de creación y aplicación de normas con el propósito de hacer efectivo

21 Es bien sabido que la diferencia entre un Estado unitario y otro descentralizado es cuestión de grado (así lo sostuvo convincentemente Hans KELSEN, por ejemplo, en su Allgemeine Staatslehre, Max Gehlen, Bad Homburg/Berlin/Zürich, 1966 (reimp. 1. ${ }^{a}$ edic), pp. 165 y 166), y que en rigor esa gradación transita de un principio unitario (sólo hay un único ordenamiento jurídico en el que es posible se integren subordenamientos parciales, territoriales o personales, que están subordinados en todo caso a aquél) a un principio federal (el ordenamiento total es el fruto de la suma de los ordenamientos parciales territoriales que se interrelacionan en un plano de igualdad), en el que el principio autonómico (España), el regionalismo (Italia antes de la reforma constitucional del año 2001) o el sistema de devolución de poderes (Reino Unido) no son sino variantes de uno u otro principio; de ahí que emplee el principio federal como expresión comprensiva de la diversas fórmulas de descentralización política entre territorios co-ordenados. Hago mía también la clásica distinción entre federalismo (el género) y Estado federal (la especie). Sobre este particular K.C. WHEARE, en su libro Federal Government, Oxford University Press, London/New York/Toronto, 1963 ( $4{ }^{a}{ }^{a}$ edic.)pp. 11 y 12, 15, en las que trata de definir los rasgos del federalismo y realiza una interesante crítica a otras opciones. No muy distinta es la definición que del mismo hace Geoffrey, SAWER, Modern Federalism, Pitman Australia, Victoria, 1976 (2. ${ }^{\mathrm{a}}$ edic., rev.), p. 1 y ss., en el que define el federal government como aquel que responde a los seis siguientes principios: un país considerado en su conjunto como un Estado-nación, con personalidad jurídico-internacional y provisto de un conjunto de instituciones que poseen autoridad sobre todo su territorio; ese país está dividido en territorios con sus propias instituciones con autoridad en esa área geográfica; el poder de gobierno está dividido entre el primero y los segundos cuyas instituciones de gobierno tienen un impacto directo sobre los ciudadanos en el marco de sus competencias; el reparto competencial se efectúa en una constitución, habitualmente escrita, dotada de cierta rigidez, que asegura que ninguno de los entes, central o territorial, puede reformarla unilateralmente (lo que implica la imposibilidad de secesiones salvo que la constitución misma las autorice); la constitución provee de reglas para la resolución de los conflictos (la regla general es que el derecho de las instituciones centrales siempre prevalece sobre el de los territorios); los conflictos y la precisión de las reglas de reparto suele competer a un órgano jurisdiccional. Consúltense las obras de R.L. WATTS, Contemporary Views on Federalism, en "Evaluating Federal System", De Villiers (ed.), Juta \& Co, 1994. Una exposición sucinta de estas diferencias se puede consultar en el trabajo, de Enric FOSSAS, facilitado amablemente por su autor, Nacional plurality and equality, p. 2 a 4. Véase también de Eliseo AJA, su libro El Estado Autonómico. Federalismo y hechos diferenciales, Alianza, Madrid, 2003 (2. ${ }^{a}$ edic.), p. 25 a 27. 
el axioma según el cual el poder público se ejerce siempre en su nombre y de la forma decidida por ellos ${ }^{22}$. Sólo así es posible garantizar jurídicamente que los poderes constituidos de carácter territorial, y el Estado central también lo es, tengan vedado disponer unilateralmente tanto del estatus básico de libertad e igualdad de los ciudadanos - los derechos fundamentales-, cuanto del orden de reparto de competencias - la forma de Estado-.

El TC español no ha sido ajeno a esta dogmática de la Gesamtverfassung, como pone de manifiesto la STC 32/1981, FJ 5: «Es obvio, para comenzar, que el término Estado es objeto en el texto constitucional de una utilización claramente anfibológica. En ocasiones (así, arts. 1, 56, 137 y en la propia rúbrica de su Título VIII, por mencionar sólo algunos ejemplos) el término Estado designa la totalidad de la organización jurídico-política de la nación española, incluyendo las organizaciones propias de las nacionalidades y regiones que la integran y la de otros entes territoriales dotados de un grado inferior de autonomía; en otras, por el contrario (así, en los arts. 3.1, 149, 150), por Estado se entiende sólo el conjunto de las instituciones generales o centrales y sus órganos periféricos, contraponiendo estas instituciones a las propias de las Comunidades Autónomas y otros, entes territoriales autónomos. Esta contraposición, que puede originar algún equívoco, no puede hacer olvidar, sin embargo, que la Constitución es la norma suprema del Estado como totalidad y que, en consecuencia, sus principios obligan por igual a todas las organizaciones que forman parte de esa totalidad" (La cursiva es nuestra) ${ }^{23}$.

También en el caso español los derechos fundamentales integran la Constitución global en su función de normas que condicionan y programan el sistema jurídico en su conjunto. Afirmaba la STC 53/1985 (FJ 4) que:

«... los derechos fundamentales son los componentes estructurales básicos, tanto del conjunto del orden jurídico objetivo como de cada una de las ramas que lo integran, en razón de que son la expresión jurídica de un sistema de valores que, por decisión del constituyente, ha de informar el conjunto de la organización jurídica y política; son, en fin, como dice el art. 10 de la Constitución, el "fundamento del orden jurídico y de la paz social". De la significación y finalidades de estos derechos dentro del orden constitucional se des-

22 El resultado no es distinto si abordamos la cuestión desde la perspectiva anglosajona. Si la nota esencial del principio federal es la distribución del poder político entre entes territoriales "COordenates", esa co-ordenación entre ordenamientos parciales territoriales sólo es posible si existe una norma superior a las constitutivas de cada uno de esos ordenamientos parciales territoriales que garantice justamente su co-ordenación. Una norma que es la que dispone de la competencia sobre las competencias y, además, asegura la interrelación de los ordenamientos parciales territoriales en una plano de igualdad. En este sentido el clásico de K.C. WHEARE, Federal Government, ob.cit., pp. 11, 13 y 14,20 y 21, 32 a 35.

23 Eduardo GARCÍA DE ENTERRÍA ha sostenido que el TC ha hecho uso de un concepto de Estado global, como el que empleó en la STC 32/1981, que permitiría considerar la forma de Estado de la CE como un "verdadero federalismo"; La Constitución y las autonomías territoriales, Revista Española de Derecho Constitucional, núm. 25, 1989, p. 17 y ss., p. 25. De ello se hace eco Gerardo RUIZ RICO, Los límites constitucionales del Estado Autonómico, Centro de Estudios Políticos y Constitucionales, Madrid, 2001, p. 29. 
prende que la garantía de su vigencia no puede limitarse a la posibilidad del ejercicio de pretensiones por parte de los individuos, sino que ha de ser asumida también por el Estado. Por consiguiente, de la obligación del sometimiento de todos los poderes a la Constitución no solamente se deduce la obligación negativa del Estado de no lesionar la esfera individual o institucional protegida por los derechos fundamentales, sino también la obligación positiva de contribuir a la efectividad de tales derechos, y de los valores que representan, aun cuando no exista una pretensión subjetiva por parte del ciudadano. Ello obliga especialmente al legislador, quien recibe de los derechos fundamentales "los impulsos y líneas directivas", obligación que adquiere especial relevancia allí donde un derecho o valor fundamental quedaría vacío de no establecerse los supuestos para su defensa. ${ }^{24}$

La ligazón entre derecho y forma de Estado está en su pertenencia a la Constitución global del Estado compuesto desde la cual condicionan negativamente su estructura territorial al imponer un límite infranqueable a la diversidad territorial. En esa medida, los derechos fundamentales son instrumento de la unidad a la que debe reconducirse la pluralidad de ordenamientos parciales que componen el Estado descentralizado. Unidad necesaria para que el Estado descentralizado (sea el Estado federal o el regional o el autonómico) exista como tal y no sea una mera confederación de Estados ${ }^{25}$.

Además, los derechos fundamentales regulan el uso del poder público (el recurso a la coerción para estabilizar expectativas) por cuanto son normas sobre la producción de normas (sistemas de habilitaciones constitucionales y reservas de ley para la delimitación y la limitación de los derechos fundamentales en los procesos de creación y aplicación de normas) y normas dotadas de eficacia jurídica (regulan directamente las relaciones jurídicas entre los sujetos del ordenamiento jurídico) que persiguen garantizar la exención de coerción en determinados ámbitos de la conducta individual o colectiva. Y esa regulación lo es del uso del poder público por todos los poderes constituidos, sea el Estado central, sean los entes territoriales. Todos ellos están sujetos positivamente a las prohibiciones de poder público contenidas en los derechos fundamentales por cuanto dichas prohibiciones son expresión de la necesidad democrática de salvaguardar frente a los poderes constituidos los fragmentos de soberanía que el individuo, sea cual sea su condición territorial, conserva en la Constitución democrática.

Repárese además en el hecho de que los derechos fundamentales no sólo condicionan la organización territorial del Estado como normas sobre las

24 Y no sólo de su dimensión objetiva, como pudiere parecer. Las dimensiones objetivas y subjetivas de los derechos fundamentales condicionan y programan a la par el ordenamiento jurídico. Por tanto, no sólo la dimensión objetiva de los derechos pertenece a la Constitución global.

25 Véase el trabajo de Antonio RUGGIERI, "Forme" e "tecniche" dell'unità, tra vecchio e nuevo regionalismo, en La definizione del principio unitario negli ordinamenti decentrati: atti del Convegno dell'Associazione di Diritto Pubblico Comparato ed Europeo, Pontignano, Universitá degli Studi di Siena, 10-11 maggio 2002, Rolla (a cura), Giappicheli, Torino, 2003, p. 91 y ss., en particular las pp. 91 a 94. 
fuentes; sino que, además, también lo hacen del ejercicio mismo de las competencias atribuidas al centro y a la periferia, ya que en las materias que son su objeto pueden ser ejercidos derechos fundamentales.

Así lo ha entendido el TC cuando en su STC 290/2000, FJ 14, afirmó que:

"De lo anterior se desprende, pues, que la exigencia constitucional de protección de los derechos fundamentales en todo el territorio nacional requiere que éstos, en correspondencia con la función que poseen en nuestro ordenamiento (art. 10.1 C.E.), tengan una proyección directa sobre el reparto competencial entre el Estado y las Comunidades Autónomas ex art. 149.1.1 C.E. para asegurar la igualdad de todos los españoles en su disfrute. Asimismo, que dicha exigencia faculta al Estado para adoptar garantías normativas y, en su caso, garantías institucionales."

Estas palabras del TC constituyen una profunda matización de las expresadas en la STC 25/1981, FJ 5, cuando sostuvo que "los derechos fundamentales no están afectados por la estructura federal, regional o autonómica del Estado ${ }^{26}$, El TC no trataba de decir que los derechos fundamentales y la forma de Estado diseñada por la CE fuesen dos cuestiones ajenas una a la otra, sino que los derechos fundamentales no estaban sujetos al reparto competencial en la medida en que, como parte de la Constitución global, se proyectan sobre el orden constitucional de reparto de competencia para reconducirlo a unidad mediante la garantía en él del estatus básico de libertad e igualdad del ciudadano.

\section{D) LA FUNCIÓN UNIFICANTE DE LOS DERECHOS FUNDAMENTALES EN LOS ESTADOS COMPUESTOS}

El federalismo como principio estructural de los Estados compuestos se cifra en estas dos ideas-fuerza que interactúan entre sí: existe un reparto de poderes entre gobiernos independientes, y, ninguno de ellos está subordinado a los otros, son poderes "co-ordenates". Es por ello que en rigor la constitución federal no es la Constitución de la federación o Estado central, sino esa Gesamtverfassung que acabamos de describir.

Dicho esto, el federalismo resulta ser un principio de organización de los poderes de un Estado $^{27}$ con arreglo a un criterio territorial, al igual que los derechos fundamentales son normas sobre el uso del poder público en los ordenamientos parciales; a saber, el del Estado central y el de los territoriales. Ambos, federalismo y derechos, son reglas sobre el ejercicio del poder público. El primero establece el reparto territorial de las funciones de dirección política y creación-aplicación de normas jurídicas condicionando la vigencia espacial de las normas del ordenamiento en función de un criterio de reparto de competencias. Los segundos, los derecho, son normas que ponen a disposición de

26 Véase el examen crítico de esta Sentencia al que somete Ignacio de OTTO y PARDO en su Estudios sobre Derecho estatal y autonómico, Civitas, Madrid, 1986, p. 159 y ss.

27 Véase el citado de K.C. WHEARE, ob.cit.., p. 15. 
la persona espacios de inmunidad frente al ejercicio de ese mismo poder público, sea cual sea el territorio en el que se encuentre, pues así lo exige el carácter indisponible al poder público de todo derecho fundamental.

Los derechos fundamentales, en consecuencia, no condicionan el reparto de competencias entre centro y periferia porque no es ese su objeto. Sin embargo introducen un criterio de uniformización como parte de la Gesamtverfassung en la medida en que su contenido es idéntico en todo el territorio del Estado (sin perjuicio, como se dirá, de que su régimen jurídico pueda ser distinto) y del que no pueden disponer los poderes públicos. En esto se cifra pues su función estructurante, y no en ser fuente de poderes implícitos para el Estado central.

A nuestro juicio el debate se desenfoca, al menos en el caso español, cuando la relación entre derechos y organización del territorio se aborda desde esta perspectiva "Competencial", viendo en el art. 149.1.1 CE una fuente de nuevas competencias transversales del Estado central en detrimento de las CCAA, o tratando de interpretar su contenido para evitar justamente este efecto. Las tantas veces citadas palabras de la STC 25/1981 (FJ 5) deben leerse como una conjuración de ese desenfoque de la cuestión y una reubicación del asunto en su lugar correcto:

"Puede decirse que los derechos fundamentales, por cuanto fundan un status jurídico-constitucional unitario para todos los españoles y son decisivos en igual medida para la configuración del orden democrático en el Estado central y en las Comunidades Autónomas, son elemento unificador, tanto más cuanto el cometido de asegurar esta unificación, según el art. 155 de la Constitución, compete al Estado".

La función estructurante de los derechos fundamentales estriba en ser criterio unificante de la posición constitucional de los ciudadanos ante los poderes públicos tanto centrales como periféricos. Los derechos fundamentales son expresión de la unidad jurídica del ordenamiento total del Estado y aseguran el equilibrio territorial entre sus partes. La uniformidad del contenido de los permisos constitucionales de autodeterminación de la conducta, o, si se quiere, de prohibición de poder público, garantiza que con independencia del lugar de residencia el estatus básico de libertad e igualdad del ciudadano es el mismo, ya que el objeto, contenido y límites del derecho fundamental es idéntico en todo el territorio ${ }^{28}$.

28 Esta perspectiva no está ligada a la teoría del right to exit formulada por STEWART según la cual el Estado federal, a través de la imposición a los Estados federados de una carta uniforme de derechos, asegura el equilibrio territorial entre Estados garantizando un estándar similar de protección en todo lugar a quienes precisamente no pueden abandonar el Estado federado en el que han visto restringidos sus derechos. En el fondo esta es la cuestión que resuelve el Caso Saenz de la SCt.US. Véase el trabajo de STEWART, Richard, Federalism and Rights. Federalism: Allocating Responsability between the Federal and Status Courts, Georgia Law Review, núm.19, 1985, p. 917 y ss., en especial p. 929 y ss.; y el comentario a esta Sentencia de TRIBE en su ya citado Saenz Sans Prophecy. 
De ahí también la cautela con la que debe tomarse el ejemplo norteamericano e incluso el alemán. Entre alguna de las interesantísimas cuestiones que plantea Akhil Reed Amar quiero destacar ahora su afirmación rotunda sobre la función estructurante que para la forma de Estado federal cumplieron originariamente las Enmiendas a la Constitución norteamericana que contenían los derechos constitucionales de los estadounidenses. Nos recuerda el profesor norteamericano que el debate sobre los derechos constitucionales en los orígenes de los EEUU tuvo mucho que ver con la construcción del federalismo. La declaración de derechos no se concibió por los "padres fundadores" como una simple cuestión de reconocimiento de derechos naturales inalienables del pueblo norteamericano, sino, y ante todo, como una cuestión federal. Si se defendía la inclusión en la Constitución federal de esa declaración no era tanto por la necesidad de garantizar ciertas expectativas subjetivas, como por el propósito de dotar a los norteamericanos de un instrumento de defensa frente a los Estados, y, por qué no decirlo, de un instrumento de control de la Federación sobre aquéllos mediante el amparo de los ciudadanos ante las actuaciones de los agentes de los Estados lesivas de sus derechos constitucionales. En efecto, la interpretación habitual que le ha dado la SCt.US a la XIV Enmienda ha sido aquella según la cual la Enmienda apoderaba a la Federación para proteger frente a los Estados la esfera de autonomía individual que garantizaba la declaración de derechos, de forma que dicha Enmienda realizaba las mismas funciones que "la cláusula de comercio" en el orden constitucional de reparto de competencias entre la Federación y los Estados ${ }^{29}$.

\section{E) LOS DERECHOS FUNDAMENTALES: ¿CLÁUSULA IMPLÍCITA DE PODERES O GARANTÍA DE UNIDAD?}

Existe una cierta coincidencia en tomar a los derechos fundamentales como cláusulas implícitas de unidad del ordenamiento jurídico en cuanto garantías que son de un estatuto constitucional homogéneo de la persona frente a los poderes públicos, sean estos los centrales o los territoriales ${ }^{30}$. La

29 Akhil Reed AMAR, The Bill of Rights...ob.cit., p. 3 y ss., 181 y ss., 284 y ss. También sobre el particular y la teoría de las tres esferas autónomas (la esfera del poder estatal, la del poder federal y la de la autonomía individual) empleada por la SCT.US en su jurisprudencia sobre la XIV Enmienda consúltese Laurence TRIBE, American Constitutional Law, Foundation Press, Mineola, New York, 1988 (2. ${ }^{a}$ edic.), p. 554 y ss. Puede consultarse un análisis concienzudo de la cláusula de comercio en el libro de Ignacio BORRAJO INIESTA, Federalismo y unidad económica. La cláusula de comercio de la Constitución de EEUU, INAP, Alcalá de Henares, 1986. últimamente, Diane McGIMSEY, The Comerse Clause and Federalism after Lopez and Morrison: The Case for Closing the Jurisdiction-Element Loophole, California Law Review, Vol. 90, 2002, p. 1675 y ss.

30 Laurence H. TRIBE, American Constitutional Law, ob.cit., p. 528; y Antonio RUGGIERI, Neorregionalismo, dinámica normativa y derechos fundamentales, Revista Vasca de Administración Pública, núm. 65 (I), p. 177 y ss., p. 206. Sin embargo no es éste el criterio empleado por la doctrina española que se ha ocupado del asunto. Ésta ha tendido a reconducir la cuestión a la garantía de la igualdad de los ciudadanos en el marco del orden constitucional de reparto de com- 
Sentencia de la SCt.US Toomer v. Witsell ${ }^{11}$ sostuvo, al interpretar la IV Enmienda CEEUU, que los derechos constitucionales eran el "cemento" de la Unión de los EEUU; la igualdad de privilegios e inmunidades en todo el territorio del Estado constituía el pilar sobre el que se edificaba la unidad de la Federación ${ }^{32}$.

Pero esta afirmación, dotada de una asepsia sólo aparente, siempre ha escondido una atribución de poderes implícitos a la Federación para hacer efectiva esa unidad del Estado en la garantía de los derechos constitucionales del ciudadano - para nosotros, sus derechos fundamentales-. En cierto modo tanto de lo mismo hizo el TC, quizá sin saberlo, al mencionar el art. 155 CE en el FJ 5 de su STC 25/198133. Con esa mención parecía reconocer en la preservación de la unidad una fuente de poderes implícitos a favor del Estado central.

Pues bien, esta es la idea más extendida en lo relativo a la función estructurante de los derechos fundamentales. La unidad del Estado descentralizado territorialmente se alcanza a través de la garantía de los derechos fundamentales, iguales para todos los residentes en el territorio del Estado, quienes no podrán ser discriminados por razón de su procedencia. Una garantía que le corresponde hacer efectiva en el conjunto del territorio al Estado central. De ello se deduce sin aparente dificultad (como se hizo con las exigencias de la unidad económica y de mercado en la CE) que los derechos fundamentales son competencia exclusiva del Estado central. Dicha competencia estatal sobre el estatus de libertad e igualdad del ciudadano sería al tiempo transversal y vertical, ya que habilitaría al Estado para regular cualquier materia, incluso las exclusivas de los entes territoriales con el fin de salvaguardar los derechos (transversalidad), y para limitar/condicionar las compe-

petencias. Un buen ejemplo puede ser el Capítulo II del libro de Gerardo RUIZ RICO, Los límites constitucionales del Estado Autonómico, o.cit., en el que encuadra el análisis de los arts. 139 y 149.1.1 CE en "la dimensión territorial del principio de igualdad" como límite al Estado autonómico.

31 SCt.US 385 U.S. 395 (1948). Sobre esto una vez más Lawrence H. TRIBE, American Constitucional Law, ob. cit., p. 528.

$32 \mathrm{El}$ TC ha empleado en muchas ocasiones la idea de la garantía de la "posición jurídica fundamental del ciudadano" ligándola a los arts. 139 y 149.1.1 CE. Por citar una entre muchas la STC 120/1998 FJ 4 afirma que "Ahora bien, la ausencia de una monolítica uniformidad jurídica no infringe necesariamente los arts. 1, 9.2, 14, 139.1 y 149.1.1. de la Constitución, ya que estos preceptos no exigen un tratamiento jurídico uniforme de los derechos y deberes de los ciudadanos en todo tipo de materias y en todo el territorio del Estado, lo que sería frontalmente incompatible con la autonomía, sino que, a lo sumo, y por lo que al ejercicio de los derechos y al cumplimiento de los deberes se refiere, una igualdad de las posiciones juridicas fundamentales (SSTC 37/1987, fundamento jurídico 10; 43/1996, fundamento jurídico 2.)" (doctrina reiterada en las SSTC 37/1981, FJ 2; 64/1990, FJ 4, 186/1993, FJ 3, 150/1990 FJ 7 y 173/1998 FJ 20).

33 STC 25/1981, FJ 5: «Puede decirse que los derechos fundamentales, por cuanto fundan un status jurídico-constitucional unitario para todos los españoles y son decisivos en igual medida para la configuración del orden democrático en el Estado central y en las Comunidades Autónomas, son elemento unificador, tanto más cuanto el cometido de asegurar esta unificación, según el art. 155 de la Constitución, compete al Estado". 
tencias de los entes territoriales en cuyo ejercicio se puedan afectar derechos fundamentales, sin perjuicio de que esa afectación se produzca en el legítimo ejercicio de esa competencia (verticalidad)..$^{34}$

A nuestro juicio ninguna de las dos afirmaciones es correcta, al menos para el caso del sistema constitucional español.

Los derechos fundamentales no son elementos estructurantes de la forma de Estado en su hipotética condición de mecanismo de control del Estado central sobre la actuación de los entes territoriales, ni su garantía es fuente de una competencia universal a favor del Estado central. Su fin en este contexto no es el de ser un instrumento en manos del Estado central para la defensa del estatus constitucional de la persona frente al poder público de los entes territoriales; sino la de programar en sentido democrático el conjunto del ordenamiento, también de los ordenamientos parciales, asegurando en todos la uniformidad del estatuto de libertad e igualdad del ciudadano en la medida en que aquellos ordenamientos territoriales también deben ser el producto de la participación en su creación y aplicación de esos ciudadanos.

En suma, los derechos fundamentales, como parte de la Constitución global del Estado compuesto, garantizan una ciudadanía única para todo el Estado e impiden la existencia de ciudadanías territoriales diferenciadas. De ahí, que la unidad del Estado, es decir, del ordenamiento, propiciada por los derechos fundamentales (en su condición de garantías de ese estatus constitucional de ciudadano) sea una cuestión de democracia antes que de territorio; de soberanía constitucional antes que de forma de Estado.

Por eso, a nuestro juicio, la función unificante de los derechos fundamentales en la CE está ligada al art. 1 CE antes que con el art. 2 CE. Desde esta perspectiva ni el art. 149.1.1 CE ofrece al Estado central una competencia legislativa universal sobre los derechos, como si se tratare de una reserva general de desarrollo y regulación del ejercicio de los derechos fundamentales a favor del Estado central; ni es posible sujetar los derechos fundamentales a la lógica del reparto de competencias.

De un lado, y a la vista de lo establecido en el art. 53.1 y $81.1 \mathrm{CE}$, la CE no atribuye al Estado central una competencial general en el art. 149.1.1 CE para la regulación de los derechos fundamentales. El legislador orgánico, cuando desarrolla derechos fundamentales, al igual que cuando reforma la Constitución, no lo es del Estado central, sino de la Gesamtverfassung. La Ley orgánica es una norma legal del ordenamiento global con vigencia en todo el

34 No puede entenderse de otro modo esa afirmación de la STC 173/1998 según la cual, la ley estatal reguladora de las condiciones básicas para el disfrute en condiciones de igualdad de los derechos del art. 149.1.1 CE puede invalidar las normas autonómicas preexistentes si la contradicen, sin perjuicio de que estas últimas pudieran ser perfectamente constitucionales hasta la promulgación de la ley estatal. El TC ha llegado a derivar del art. 149.1.1 CE una garantía de las condiciones básicas del ejercicio de la actividad económica de la que ha deducida ni más ni menos un principio constitucional de unidad de mercado del que se derivan poderes implícitos a favor del Estado central que han permitido extender sus competencias exclusivas y restringir las de las CCAA (así por ejemplo en la STC 64/1990). 
territorio del país y única competente para desarrollar el contenido de un derecho fundamental.

La cuestión es muy otra cuando se trata de regular el ejercicio de los derechos. El art. 53.1 CE es una norma que regula una habilitación tanto para el Estado, esta vez sí, central, como para las CCAA. La ley estatal central y la ley autonómica son normas idóneas para regular el ejercicio de los derechos fundamentales (STC 37/1981 FJ 2). Sucede, entonces, que la forma de establecer qué compete a quién depende justamente del reparto competencial fijado en el bloque constitucional. No son los derechos los que se reparten, sino su régimen jurídico; esto es, la regulación de su realización en la práctica. Un ejercicio que necesariamente se da en la realidad; realidad que está sujeta a reparto competencial. Así pues, tendrá la competencia para regular el ejercicio de un derecho fundamental aquel que sea el titular de la materia en la que ese ejercicio deba regularse.

Como hemos tenido ocasión de afirmar en otro lugar ${ }^{35}$, el art. 53.1 CE no atribuye al Estado central una competencia genérica y universal para regular el ejercicio de los derechos fundamentales, desligada de las materias competenciales del Estado central, "que incluso se sobreponga a las regulaciones sectoriales del ejercicio del derecho en cuestión efectuadas por las Comunidades Autónomas. Nada ha dicho expresamente sobre este extremo el TC y las veces que se ha pronunciado ha sido para vincular la ley estatal o al desarrollo de los derechos del art. 81.1 CE (STC 173/1998) o al art. 149.1.1 CE (SSTC 37/1981, 290/2000). A nuestro juicio, y dado que el art. 149.3 no atribuye ninguna competencia universal al Estado ni siquiera para crear normas supletorias (SSTC 15/1989, 118/1996), éste carece de esa competencia genérica a salvo lo dispuesto en el art. 149.1.1 CE. Como dice la citada STC 37/1981, la ley del art. 53.1 CE sólo será ley de Cortes Generales cuando con esa regulación genérica del ejercicio de los derechos el Estado pretenda establecer las condiciones básicas que garanticen la igualdad de todos los españoles en su ejercicio. Para el resto de los casos, la regulación del ejercicio de un derecho fundamental será competencia de aquel que tenga atribuida la de la materia en la que se encuadra dicha regulación. Así lo expresa también la STC 173/1998 (FJ 7) respecto del art. 81.1 CE:

«Pues bien, uno de los criterios fundamentales que, junto a los ya mencionados, ha orientado la realización de esta tarea de definición sistemática ha sido la de reservar al Estado ex art. 81.1 C.E. la regulación de los aspectos esenciales, el desarrollo directo del derecho fundamental considerado en abstracto o en cuanto tal", en tanto que se atribuye la regulación de la "materia" sobre la que se proyecta el derecho al legislador ordinario, estatal o autonómico, con competencias sectoriales sobre la misma (SSTC 127/1994, 61/1997 y, en relación concretamente con el derecho de asociación, SSTC 67/1985 y 157/1992)".

35 Véase BASTIDA, VILLAVERDE, REQUEJO, PRESNO, ALÁEZ, FERNÁDEZ, Teoría general de los derechos fundamentales, ob.cit., p. 170. 
El conveniente abandono del modelo de, en palabras de Francisco CAAMAÑO, Estado unitario subyacente ${ }^{36}$ tras las SSTC 118/1996 y 61/1997 que alteraron el sentido que hasta ese momento se le daba a la cláusula de supletoriedad del art. 149.3 CE, se frustraría al reintroducirse la competencia legislativa universal del Estado central por medio del art. 149.1.1 CE. Los derechos se concebirían como asunto del Estado central que velará por su respeto en todo el territorio del Estado, asegurando su uniformidad, y asumiendo la condición de único poder público habilitado para regular el contenido y ejercicio de los derechos fundamentales. El legislador estatal universal sería el legislador de los derechos fundamentales en la medida en que no existe prácticamente materia alguna que de un modo u otro no afecte a los derechos del Título I CE.

No es éste ni siquiera el sentido literal del art. 1491.1.1 CE. Pero que este planteamiento sea erróneo, no da razón a quienes, yendo al otro extremo, estiman que los derechos fundamentales son, como cualquier otra cosa, una "materia competencial". La función estructurante de los derechos fundamentales se limita a ser un criterio de uniformidad en el Estado compuesto al estar ubicados en su Constitución global: toda persona tiene los mismos derechos fundamentales en todo el territorio del Estado. En esa medida, los derechos fundamentales no son cosa del Estado central ni su protección inviste a éste de género alguno de poderes implícitos transversales y verticales sobre los territorios autónomos. Los derechos fundamentales son cosa del $\mathrm{Ge}$ samtstaat.

\section{LA GARANTÍA DE LA UNIDAD DEL ESTADO A TRAVÉS DE LOS DERECHOS FUNDAMENTALES}

Ya hemos dicho que en las Constituciones democráticas la dignidad de la persona se cifra en la garantía de su estatus de ciudadano libre e igual, que la CE eleva a fundamento de la sociedad y el Estado españoles (art. 10.1 CE). En este sentido los derechos fundamentales en los que se precisa ese estatus constituyen el "cemento" del Estado compuesto ${ }^{37}$; o en palabras de RUGGIERI, son "la constante" que redefine en abstracto el modelo constitucional de reparto de competencias entre centro y periferia y las manifestaciones concretas

36 Francisco CAAMAÑO, El abandono de lo básico: Estado autonómico y mitos fundacionales, Anuario de derecho Constitucional y Parlamentario, núm. 12/13, 2000-2001, p. 87 y ss., p. 95.

37 SCt.US Toomer v. Witsell, 385 U.S. 395 (1948). RUGGIERI menciona que la Constitución expresa esa unidad que se mantiene aseguranda lo que el denomina "condiciones elementales de vida no diversos en cuanto al goce de derechos fundamentales... entre los ciudadanos" (Forme" $e$ "tecniche" dell'unità, tra vecchio e nuevo regionalismo, en La definizione del principio unitario negli ordinamenti decentrati: atti del Convegno dell'Associazione di Diritto Pubblico Comparato ed Europeo, Pontignano, Universitá degli Studi di Siena, 10-11 maggio 2002, Rolla (a cura), Giappicheli, Torino, 2003, p. 91 y ss., p. 92). 
de su ejercicio ${ }^{38}$. La ciudadanía es única e idéntica en todo el territorio del Es$\operatorname{tado}^{39}$.

Y esto es capital para el Estado constitucional democrático de Derecho. Parafraseando aquí a Tribe, ni el Estado central ni los entes territoriales poseen el poder constitucional para definir la identidad del colectivo de personas a las que cabe calificar de ciudadanos y debe tratar en condiciones de igualdad como miembros de pleno derecho de la comunidad, porque esa función es propia únicamente de la Geseamtverfassung; esto es, de la voluntad del Pueblo soberano que es el único capaz para identificar quienes son los individuos que deben participar en los procesos de creación y aplicación de normas mediante la definición de su estatuto básico de ciudadano libre e igual. No es coherente con el principio democrático que los poderes constituidos puedan elegir irrestrictamente ante quién son responsables políticamente disponiendo justamente del contenido jurídico de aquel estatus. Todo lo contrario, ese estatus es el que determina ante quién los entes dotados con poder público son políticamente responsables. De ahí la función unificante de los derechos fundamentales como normas que garantizan la incolumidad de aquel estatus en el seno de un Estado constitucional democrático de Derecho y territorialmente compuesto.

Cierto que la unidad del Estado se puede alcanzar por vías bien distintas. Y no es menos cierto que esa unidad siempre se ha identificado con las palabras del art. $2 \mathrm{CE}$ a las que se les ha dado un sentido predominantemente político: «La Constitución se fundamenta en la indisoluble unidad de la Nación española, patria común e indivisible de todos los españoles". No es menor el problema de interpretación jurídica que suscita este precepto ${ }^{40}$. Pero cabe

38 Véase su Neorregionalismo, dinámica normative y derechos fundamentales, Revista Vasca de Administración Pública, núm. 65 (I), p. 177 y ss., p. 206.

39 No se nos escapa que esta afirmación pudiere entrar en contradicción con la "ciudadanía autonómica" definida en los EEAA. El TC algo ha dicho sobre este particular en relación con lo razonable que resulta exigir la "condición política" autonómica a los efectos del ejercicio de los derechos de sufragio para asegurar una cierta homogeneidad de intereses entre electorado, cuerpo electoral y representantes; SSTC 60/1987, 107/1990, 25/1992 y últimamente la 86/2003. Véase también Francisco BASTIDA FREIJEDO, La soberania borrosa, ob.cit., p. 417 y ss. En realidad lo que las CCAA pueden establecer son "ciudadanías" basadas en la residencia a los efectos de delimitar su ámbito personal e identificar los destinatarios de ciertas obligaciones y cargas (especialmente tributarias) y los titulares de derechos, particularmente, políticos. En ningún caso las CCAA podrían establecer una "nacionalidad autonómica" que permitiese calificar a los no nacionales autonómico de extranjeros. Justamente, esa vía la veda la garantía uniforme del estatus de ciudadano libre e igual en todo el Estado. Sobre esta cuestión véase también el libro citado Miguel Angel CABELLOS ESPIÉRREZ, Distribución de competencias..., p. 35, not. 69. Véase también el trabajo de José WOEHRLING Estats composes et droits fonamentaux, en "Derechos Constitucionales y Formas Políticas. Actas del Congreso sobre derechos constitucionales y Estado autonómico", p. 315 y ss., Aparicio (Coord.), Cedecs, Diputación de Tarragona, Barcelona, 2001; en especial p. 345 y ss. en el que habla sobre el efecto que la función unificante de los derechos tiene sobre la consolidación de una identidad nacional en detrimento de las identidades regionales.

40 Cítese aquí el trabajo de Xacobe BASTIDA FREIJEDO, La Nación española y el nacionalismo constitucional, Ariel, Barcelona, 1998, en el que saca a la luz la genealogía del art. 2 CE; el 
aventurar una interpretación que sea coherente con la posición de supremacía de esa Constitución que supuestamente se "fundamenta" en esa unidad y que explica ese principio unitario como un elemento esencial del principio federal, que también recoge ese art.2 CE, en relación con los derechos fundamentales ${ }^{41}$.

Jurídicamente sólo es posible una unidad: la del ordenamiento jurídico; y en el caso de los Estados compuestos, esa unidad no es sino la del orden jurídico total al que se reconducen los distintos ordenamientos jurídicos parciales que lo componen. Reconducción que se hace posible porque incluso en los Estados compuestos (que no sean una simple agregación de Estados soberanos, esto es, una confederación) sólo hay un soberano que ha expresado su voluntad normativa en la Gesamtverfassung. El principio de unidad, jurídicamente, sólo expresa que hay un único punto de imputación de la validez de todas las normas y actos de los ordenamientos parciales que componen el Estado compuesto ${ }^{42}$.

En esa medida, la Gesamtverfassung es un instrumento de integración de los ordenamientos jurídicos y de los intereses y expectativas que en ellos se realizan en una unidad superior ${ }^{43}$. En consecuencia, y la CE no es ajena a este

estudio sistemático que hace del principio unitario en la CE Enric FOSSAS en su trabajo Il principio unitario come reserva di competenza allo Statu centrale secondo la giurisprudenza costituzionale, en "La definizione del principio unitario negli ordinamenti decentrati: atti del Convegno dell'Associazione di Diritto Pubblico Comparato ed Europeo, Pontignano, Universitá degli Studi di Siena, 10-11 maggio 2002", ROLLA (a cura), Giappicheli, Torino, 2003, p. 133 y ss. Consúltese también el Cap. 2 del libro de Francisco TOMÁS Y VALIENTE, El reparto competencial en la jurisprudencia del Tribunal Constitucional, Tecnos, Madrid, 1988, en el que trae a colación el momento integrativo que debe verse en ese precepto tratando de enlazar con el Estado integral de la II. ${ }^{a}$ República (p. 29 y ss.); véase también su Soberanía y Autonomía en las Constituciones de 1931 y 1978, en "Obras Completas", Vol. III, p. 1837 y ss., Centro de Estudios Constitucionales, Madrid, 1997.

41 Este aparente contrasentido se explica en cuanto se repare en la circunstancia de que la instauración de una estructura federal persigue integrar en una unidad lo plural y distinto. De ahí que, pese a la apariencia, la forma federal de Estado cimenta uno de sus pilares en el principio de unidad. No extraña entonces la coincidencia en este extremo de autores como CARRÉ DE MALBERG, Teoría general del Estado, Fondo de Cultura Económica, UNAM, México, 1998 (reed), pp. 109 y ss., 124 y ss.; NAWIASKY, Hans, Allgemeine, ob.cit., p. 155, y especialmente pp. 157 y 159; o K.C. WHEARE, Federal Government, ob. cit., Cap. I., p. 36. Modernamente, Konrad HESSE, Der unitarische Bundesstaat, en "Ausgewälte Schriften", Heidelberg, 1984; o en España José Juan GONZÁLEZ ENCINAR, El Estado unitario-federal. La autonomía como principio estructural del Estado, Tecnos, Madrid, 1985.

42 Véase Hans KELSEN, Allgemeines, ob. cit., p. 164 y ss. En este mismo sentido Hans NAWIASKY, Allgemeine, ob. cit., p. 155 y ss.; y CARRE DE MALBERG, Teoría general, ob.cit., p. 124 y ss.

43 Sobre este momento integrativo, y no sin profundas discrepancias sobre el particular, véase Rudolf SMEND, Constitución y Derecho Constitucional, Centro de Estudios Constitucionales, Madrid, 1985, passim. Una dura crítica a las teorías de Smend se puede encontrar en Hans KELSEN, Staat als Integration, Scientia Verlag, Aalen, 1994 (2. ${ }^{a}$ reedic.). Sobre la actualidad del debate político constitucional sobre el Estado compuesto como fórmula de integración de sistemas plurinacionales o multiculturales véase el libro colectivo editado por FOSSAS/FERRÁN (Eds.), Asimetría federal y Estado plurinacional, Trotta, Madrid, 1999. 
planteamiento, el principio de unidad en el Estado compuesto se funda necesariamente en la existencia de un único soberano y en el ejercicio de un único poder constituyente ${ }^{44}$.

Desde luego que el art. 2 CE puede leerse desde una perspectiva políticocultural al hilo de la idea de "Nación", o territorial, cifrada en el carácter indisoluble de la "patria" común. Pero a nuestro juicio la interpretación constitucionalmente conforme del art. 2 lo liga a la garantía constitucional del principio autonómico (hoy por hoy, federal) y a la soberanía nacional del Pueblo español del art. 1.1 CE, y aleja el principio de unidad de aquellas otras dimensiones.

En efecto, la CE en rigor desconstitucionalizó la forma definitiva de reparto territorial del poder público en España. Esto podría hacer pensar que la CE posibilitaba tanto una forma de Estado unitario como la opuesta, la de Estado compuesto. Una decisión abandonada a la libre voluntad del legislador y en esa medida sujeta de forma radical a la controversia política. Sin embargo este juicio no es correcto ya que el art. 2 CE asegura, en la unidad del Estado, la autonomía de sus territorios; es decir, constitucionaliza una forma de Estado descentralizada, de modo que lo único desconstitucionalizado es, en realidad, la decisión de acceder o no a esa autonomía político-territorial y el concreto alcance en cada caso de la autonomía consagrada en el art. $2 \mathrm{CE}$, lo que se plasmará finalmente en los Estatutos de Autonomía y restantes normas del bloque constitucional. España es un Estado único pero no unitario (SSTC $29 / 1981$ y $1 / 1982)^{45}$.

44 Estas afirmaciones son especialmente provocativas y polémicas porque el rasgo que en el sistema continental (no así en el federalismo anglosajón) ha definido a los Estados federales ha sido siempre el reconocimiento que la Constitución federal hacía de la soberanía y poder constituyente de los Estados federados que se plasmaba en sus Constituciones estatales. Este rasgo ha permitido sostener por autores tan dispares como Ignacio de OTTO Y PARDO (Escritos, p. 36 y ss.) o Enric FOSSAS (Il principio unitario, p. 134) que el Estado español no puede derivar en un Estado federal. Esto conduce derechamente a la espinosa cuestión de la soberanía en los Estados compuestos. De las palabras dichas en el tetxo es evidente que la Constitución global es la que dota de validez a los ordenamientos jurídicos parciales y a sus normas constitutivas, como es bien sabido así lo sostuvo Hans KELSEN (Allgemeine, p. 164 y ss.). Es nuestra opinión que la afirmación de que el rasgo que distingue a un Estado federal de otras fórmulas de descentralización política como la autonómica española o la de devolución británica descansa en que los Estados parte también poseen un poder constituyente propio y una Constitución soberana. Que así sea posee un valor político indudable pero es una contrasentido jurídico. Ese rasgo de las soberanías coetáneas son lastres del origen histórico confederal de muchos de los Estado federados modernos. Recurrir a ese rasgo es desde luego útil para legitimar el nuevo Estado compuesto, pero carentes de sentido jurídico. Sobre estas cuestiones véanse las ilustradoras palabras de KELSEN, Allgemaine, ob.cit. p. 116 y 198 y ss.; NAWIASKY, Allgemeine, p. 152 y ss.; y CARRE DE MALBERG, Teoria general, p. 96 y ss. También, Juan José SOLOZABAL ECHAVARRIA, El problema de la soberanía en el Estado autonómico, Fundamentos, núm. 1, 1998, p. 461 y ss.

45 Se trata, por cierto, de un debate también habido en el reino Unido al hilo de las Devolution Acts. Para la Doctrina británica es claro que tras estas leyes de devolución de poderes a escocia, Gales e Irlanda, el Reino Unido ha dejado de ser un Estado unitario para serlo compuesto, pero sin dejar de ser un único Estado. Véase en general, Vernon BOGDANOR, Devolution in the United Kingdom, Oxford University Press, Oxford, 2001, p. 34 y ss. 
De otro lado, la unidad del Estado es una cuestión de soberanía diseñada en el art. 1.2 CE al afirmar que en el estado español, vale decir, en el ordenamiento jurídico español no hay más soberano nacional que el Pueblo español del que emanan todos los poderes del Estado, los centrales y los territoriales ${ }^{46}$. Y no deben interpretarse de otro modo las cautelosas referencias que ha hecho el TC al principio de unidad en Sentencias como las 4/1981 (FJ 3), 35/1982 (FJ 2), 38/1982 (FJ 2).

Precisamente, si el principio de unidad tiene este contenido jurídico, y está ligado a la soberanía nacional del Pueblo español del art. 1.2 CE, en modo alguno cabe entender que en el art. $2 \mathrm{CE}$ se establece género alguno de reserva de competencia a favor del Estado central o que el art. 149 CE contiene el núcleo de los poderes soberanos de ese Estado. Pensarlo así conlleva rechazar la existencia de una Constitución global, obra de la voluntad del Pueblo español soberano, e identificar a ese soberano con el Estado central. Si así fuese, obviamente el Estado de las Autonomías no sería una manifestación más del principio federal. Pero es más, difícilmente se podría argumentar que la relación entre ese Estado central soberano y las CCAA carentes de soberanía debe ser en todo caso horizontal.

Dicho esto, la dignidad ciudadana del Estado democrático de Derecho, que cobra vida en los derechos fundamentales que garantizan el estatus de libertad e igualdad del ciudadano, son un criterio de la unidad del ordenamiento jurídico por cuanto condicionan la validez de todas sus normas y actos de creación y aplicación de esas normas. En esa medida los derechos fundamentales son parte del principio democrático, principio estructural (condicionante y programador) del sistema jurídico en su totalidad y a través suyo se garantiza la unidad de ese sistema en la voluntad constituyente del Pueblo soberano que ha querido estabilizar ciertas expectativas de autodisposición de la conducta individual o colectiva frente a cualquier poder público y en todo el territorio del Estado. La dignidad ciudadana es una y única en el Estado compuesto español ${ }^{47}$.

En suma, y en contra de lo afirmado por Carl SCHMITT, la unidad del Estado no descansa a nuestro juicio en la existencia de un determinado pueblo, valga decir ahora, "nación española", sino en una Constitución democrática que garantiza la dignidad ciudadana a toda persona sea cual sea el territorio del Estado en el que resida o del que proced $a^{48}$. O dicho de otro modo, la

46 En este sentido, no sin cautelas, se pueden leer las SSTC $173 / 2002$ y 3/2003. Véase el libro citado de Francisco TOMÁS Y VALIENTE, El reparto competencial..., ob.cit., p. 30.

47 Nada hay aquí que contradiga las afirmaciones de Ignacio de OTTO Y PARDO, sobre la positividad constitucional de los derechos fundamentales como única causa de su función unificante (Escritos, p. 161 y 162). Efectivamente, los derechos fundamentales son ese estatuto único en la medida en que son normas constitucionales que vinculan por igual a todos los poderes públicos, incluidos los autonómicos. Pero por sí sola, esta afirmación no basta para explicar la función que cumplen esos mismos derechos fundamentales en el Estado compuesto cuando además es democrático.

48 Carl SCHMITT, Verfassungslehre, Duncker \& Humblot, Berlin, 1991 (facsml.1928), pp. 35 y 45 . 
unidad del Pueblo en el Estado democrático deviene de la igualdad de todos en la dignidad ciudadana.

Así pues, esta función unificante no deriva en rigor de un art. 149.1.1 CE que atribuya al Estado central el deber de uniformizar el régimen jurídico de los derechos fundamentales (lo que como es bien sabido ni siquiera exige el art. 139.1 CE), sino de la indisponibilidad de los derechos fundamentales. Una indisponibilidad que, es cierto, deriva de su propia condición de constitucionales. Pero esa fundamentalidad de los derechos, su indisponibilidad, posee un fundamento democrático innegable (asegurar el estatus básico de ciudadano libre e igual); por eso son la mejor técnica de protección de la dignidad ciudadana. Y por esa razón no es posible un Estado democrático sin una Constitución que no posea una declaración de derechos fundamentales.

En lo que ahora importa, esa constitucionalización de los derechos y su fundamentalidad son fuente de unidad en el Estado porque aseguran la igualdad de todos en esa dignidad ciudadana. Los derechos fundamentales sólo poseen un único contenido constitucionalmente garantizado en abstracto en el precepto constitucional del que son titulares todos los ciudadanos en condiciones de igualdad y del que no pueden disponer ni el Estado central ni las CCAA. No hace falta un art. 139 o 149.1.1 para garantizar que esto sea así porque tal consecuencia deriva de la constitucionalización y la fundamentalidad de los derechos en la Constitución global. La definición constitucional del derecho fundamental es igual para todo el territorio del Estado, y en ello se cifra su unidad jurídica ${ }^{49}$.

\section{DERECHOS FUNDAMENTALES Y REPARTO COMPETENCIAL}

El reparto competencial es aquel que define qué competencias posee cada cual en el marco del Estado compuesto. Como tal técnicamente no es más que una forma de regular el poder público, o si se quiere de forma más gráfica, el uso de la coerción para respaldar expectativas de conducta; y de hacer esa regulación en términos territoriales.

En puridad, en los Estado compuestos lo que se reparte no son tanto competencias como materias sobre las que se ejercen ciertas competencias ${ }^{50}$.

49 Esta función unificante lo único que impone es una igualdad de las posiciones jurídicas fundamentales, pero no, desde luego, una absoluta identidad en su régimen jurídico (en este sentido SSTC 37/1987, de 26 de marzo, FJ 10; 150/1990, de 4 de octubre, FJ 7; 186/1993, de 7 de junio, FJ 3; 227/1993, de 9 de julio, FJ 4; STC 131/2001 FJ 4).

50 Esto es así en la medida en que cualquiera de las variantes de reparto de poder por listas entre Estado central y entes territoriales tratan, en principio, de atribuir a uno de ellos todas las competencias (potestades jurídicas) sobre una materia (en este sentido cabe entender en ocasiones el término de competencia "exclusiva", aquella que recae sobre una materia respecto de la que ningún otro ente político posee potestades jurídicas). De este modo se logra la co-ordenación horizontal entre los entes territoriales, ya que si el reparto se limita a las competencias mismas (a las potestades) para proyectarse sobre una misma materia, entonces aquella horizontalidad 
A salvo aquellos casos, que no son extraños al modelo territorial de Estado de la $\mathrm{CE}$, en los que sobre una misma materia lo que se distribuyen son justamente las funciones (legislación, ejecución, por ejemplo el art. 1491.1.7 régimen laboral; bases, desarrollo, caso del art. 149.1.17 —Seguridada Social—) $)^{51}$. Es decir, el objeto del reparto es una materia determinada, y por materia hay que considerar una realidad, física, social, económica, institucional, política o jurídica. Dicho con las palabras de la STC 32/1981 (FJ 5):

"El apartado primero del art. 149 de la Constitución está construido por referencia a materias o actividades concretas del poder respecto de determinados fines sociales, con la única y notable excepción precisamente del párrafo decimoctavo, en la que la referencia es justamente a una acción por así decir reflexiva del Estado, esto es, a la que el mismo lleva a cabo en relación al apartado administrativo que constituye su instrumento normal de actuación" (la cursiva es nuestra) ${ }^{52}$.

La materia es, pues, el conjunto de actividades, funciones o instituciones jurídicas relativas a un sector de la vida social, como afirmó la STC 123/1984 (FJ 2). Un sector de la vida social jurídicamente calificado y acotado sobre el que recaen competencias repartidas o compartidas por el Estado central y las CCAA.

Parece evidente que un derecho fundamental no es una materia competencial porque el sector de la vida social que constituye la materia objeto del orden constitucional de reparto de competencias será a lo más el objeto del derecho fundamental.

Por otro lado, ese orden de reparto de competencias regula el poder público como también lo hacen los derechos fundamentales. Pero uno y otro de

esencial al principio federal se distorsiona. De hecho, el federalismo cooperativo trata de atajar esta distorsión en los Estados compuestos en los que el sistema de reparto es concurrencial. Véase sobre esto Walter, RUDOLF, Kooperation im Bundesstaat, "Handbuch des Staatsrechts", Isensee/Kirchhof (Hrs..), Bd.IV, p. 1091 y ss., C.F. Müller, Hiedelberg, 1990; y los nuevos rumbos del federalismo cooperativo en Alemania en Erhard DENNINGER Tendenze del Federalisno in Germania, Spisa, Università di Bologna, Clueb, Bolognia, 1998, y más modernamente Klaus Jügen NAGEL, El federalismo alemán. ¿Más cooperación o nueva asimetría?, Revista de Estudios Políticos, núm. 118, 2002, p. 65 y ss.

51 Sigue siendo un libro de consulta indispensable para el estudio de estas cuestiones la obra de Santiago MUÑOZ MACHADO, Derecho Público de las Comunidades Autónomas, Civitas, Madrid, 1982, Caps. IV. Igualmente útil a estos efectos es el libro de Ignacio de OTTO Y PARDO, Derechos fundamentales ob.cit., p. 87 y ss.; y el de Francisco TOMÁS Y VALIENTE, El reparto competencial en la jurisprudencia del Tribunal Constitucional, Tecnos, Madrid, 1988, pp. 67 y ss. También es de consulta obligada el libro de Carles VIVER PI SUNYER, Materias competenciales y Tribunal Constitucional, Ariel, Barcelona, 1993, passim.

52 Sobre esta noción véanse los trabajos citados de Carles VIVER PI SUNYER, Materias competenciales, pp. 18 y ss., en especial pp. 23 y ss., 27 y ss., 37 y ss.; y el de Marc CARRILLO, La noción de "materia", p. 109 y ss. Estos dos autores propugnan una definción objetiva de las materias competenciales que aleje de su interpretación, decisiva para el reparto de competencias, de toda veleidad voluntarista $\mathrm{O}$, dicho, en fin, con toda claridad, para evitar que sea el TC quien realice el reparto de competencias y no el bloque constitucional. También es de interés el citado de Francisco TOMÁS Y VALIENTE, El reparto competencial, p. 105 y ss. 
forma diversa. Los derechos fundamentales regulan el uso del poder público para prohibirlo en ciertos sectores de la vida social y, no obstante, habilitar a ciertos órganos del Estado para intervenir en ese sector de la vida con el propósito, o bien de limitar el derecho fundamental privando de su protección a una porción de ese sector de la vida social, o bien delimitando el propio derecho fundamental y definiendo, en consecuencia, precisamente el sector de vida social sobre el que actúa su exclusión de poder público, o bien para regular el ejercicio del derecho fundamental en el sector de la vida social que constituye su objeto, o bien, finalmente, de crear instrumentos de garantía para su pleno disfrute en él.

Y todo este conjunto de habilitaciones se sujeta a las reglas de atribución de las mismas previstas en el diseño del sistema de fuentes contenido en la Constitución. Y esa remisión puede ser al sistema general de fuentes, o aquellas reglas específicas que haya establecido la norma constitucional para el caso de habilitaciones relativas a los derechos fundamentales.

Es en este entramado en el que han de encontrarse los derechos fundamentales y el orden constitucional de reparto de competencias: en el sistema de fuentes, en general, y en las reglas sobre habilitaciones normativas relativas a derechos fundamentales, en especial. Las páginas que siguen van a analizar esta estructura.

\section{A) LA INDISPONIBILIDAD DE LOS DERECHOS FUNDAMENTALES}

Este es, desde luego, el punto de partida: la condición de indisponible de todo derecho fundamental. Un derecho fundamental es un poder jurídico de autodeterminación a disposición del individuo titular del derecho, pero indisponible al legislador, que recae, o bien sobre una conducta a realizar en determinado ámbito de la realidad, pudiendo hacer valer jurisdiccionalmente el permiso constitucional de llevarla a cabo, o bien sobre un deber jurídico a cargo de terceros, pudiendo hacer valer jurisdiccionalmente una prohibición de poder público en los términos que establece un precepto constitucional indisponible al legislador ${ }^{33}$.

Lo que importa destacar ahora es su dimensión de poder jurídico indisponible al legislador. En esta nota los derechos fundamentales expresan su

53 Véase el estudio de Ignacio VILLAVERDE MENÉNDEZ, Concepto, contenido, objeto y limites de los derechos fundamentales, en "La Democracia constitucional. Estudios en homenaje al profesor Francisco Francisco Rubio Llorente", Aragón/Jiménez/Solozábal (Coord.), Congreso de los Diputados, Tribunal Constitucional, Universidad Complutense de Madrid, Fundación Ortega y Gasset, Centro de Estudios Políticos y Constitucionales, Madrid, 2002, Vol.I, pp. 317 a 364 . También, BASTIDA, VILLAVERDE, REQUEJO, PRESNO, ALÁEZ, FERNÁDEZ, Teoría general de los derechos fundamentales en la Constitución de 1978, Tecnos, Madrid, 2004, p. 30 y ss. También el libro de Teresa FREIXES SANJUÁN, Estructura jurídica y función constitucional de los derechos. Introducción al sistema constitucional de los derechos en la Constitución Española de 1978, PPU, Barcelona, 1993, p. 31 y ss., que ofrece una visión distinta a la aquí planteada. 
condición de norma perteneciente a la Constitución global y, en consecuencia, desligadas de los legisladores territoriales.

Los derechos fundamentales son los que el Pueblo soberano ha querido que sean y constituyen el estatuto básico de libertad e igualdad del ciudadano en el ordenamiento jurídico democrático. El propio TC ha afirmado que fuera de la CE no hay derechos fundamentales (SSTC 84/89 y 245/91). Su especial posición en el ordenamiento jurídico respecto de la forma de Estado y su sistema de fuentes en su indisponibilidad para el legislador, sea éste el estatal, sea el territorial. Es esa plena indisponibilidad lo que, precisamente, distingue a los derechos fundamentales de otros derechos, que podrán ser constitucionales por su ubicación en la norma suprema, pero su existencia depende de una decisión legislativa (por ejemplo, los derechos constitucionales regulados en los arts.105, 121, 125 ó 129 CE).

Ese es precisamente el sentido de la indisponibilidad de los derechos, que su existencia en el ordenamiento jurídico, luego su eficacia directa, no depende ni puede depender de una decisión legislativa. En consecuencia, sustraídos del poder de innovación y modificación que posee el legislador, estatal o territorial, su único contenido necesariamente debe ser el definido con mayor o menor grado de abstracción en la Constitución que los contiene. Para decirlo con el rigor debido, pues la circunstancia de que el contenido del derecho fundamental esté ya en la norma constitucional no deriva de su indisponibilidad para el legislador, el legislador estatal o el territorial no disponen ni de la existencia del derecho fundamental ni de su contenido, pues como elemento estructural de la Constitución democrática de Derecho, es ésta (en fin, la voluntad del Pueblo soberano), la Gesamtverfassung, la que impone la existencia del derecho en todo el ordenamiento (irradiando sus dimensiones subjetivas y subjetivas sobre el conjunto del sistema jurídico) y con un contenido que sólo la Constitución global ha definido y puede redefinir a través de la reforma constitucional54.

Esa fundamentalidad de los derechos fundamentales, su indisponibilidad, convierte al contenido constitucionalmente definido del derecho fundamental en un límite material a la ley que los puede desarrollar, limitar, regular su ejer-

54 No se puede negar que en la dogmática alemana, que inspira claramente esta tesis sobre los derechos fundamentales, se ha reabierto no hace mucho el debate sobre el concepto de derecho fundamental y su teoría propuestos por ALEXY. Un debate del que se hace eco por un lado el propio Robert ALEXY en su Epilogo a la Teoría de los derechos fundamentales, Revista Española de Derecho Constitucional, núm.63, 2002, p. 13 y ss.; al que responde el nuevo trabajo de ErnstWolfgang BÖCKENFÖRDE, Schutzbereich, Eingriff, Verfassungsimmanente Schranken,... ob.cit., p. 165 y ss. El modelo anglosajón responde a unos criterios y tradiciones que aminoran su utilidad para esa labor de construcción dogmática, baste, por ejemplo, con examinar los términos del debate habido entre M.D. ADLER y R.H. FALLON sobre la estructura de los "constitucional rights"; ADLER, Rights Against Rules: The Moral Structure of American Constitutional Law, Michigan Law Review, núm. 1, 1998, y su Rights, Rules and the Structure of Constitutional Adjudication: A Response to Prolessor Fallon, Harvard Law Review, Vol. 113, 2000, pp. 1371 y sigs.; y de FALLON, As-Applied and Facial Challenges and Third-Party Standing, Harvard Law Review, Vol. 113, 2000, pp. 1321 y sigs) 
cicio o promoverlo. Esto es, la expansividad materialmente ilimitada de las reservas de ley no sólo está limitada externamente por las restantes normas constitucionales, sino que, además, su propia materia, cuando es un derecho fundamental, impone restricciones al poder de regulación del legislativo, quien sumará a aquellos límites los que le erigen el objeto y contenido del derecho fundamental que vienen abstractamente definidos en la Constitución.

Conviene reparar en la circunstancia de que, mientras que para el legislador de los derechos fundamentales los límites a su poder de regulación derivan del propio objeto que pueden regular; para el legislador de las materias competenciales, éstas no imponen límite alguno a su poder. Es decir, la expansividad material ilimitada del legislador de los derechos fundamentales está acotada justamente por la materia que regulan. El objeto de la ley relativa a derechos fundamentales viene predefinido por la Constitución.

Sin embargo, para el legislador de las materias competenciales, el objeto de su ley no impone límites a la expansividad de dicha forma jurídica. La materia aguas o pesca no limita por definición a la ley, estatal o autonómica, que deban regularlas. Antes al contrario, en buena medida, qué sean jurídicamente las materias, esto es, qué sea "aguas" o "pesca" y su modo de existencia en el ordenamiento está a la plena disposición del legislador, estatal o territorial según el orden de reparto competencial diseñado en la Constitución. El respeto a este orden es el único límite a esa expansividad de la legislación estatal o territorial cuando se trata de regular materias competenciales ${ }^{55}$.

Abundando en esta idea, la función de un derecho fundamental es justo la contraria a la que poseen las materias en el modelo territorial del Estado. El derecho fundamental persigue sustraer ciertos espacios de la vida social del poder público, incluido el ejercido e impuesto por medio de la legislación. Justo contrario a la función que desempeñan las materias, que es la de delimitar el sector de la vida social que queda a la disposición de determinado poder público que tendrá competencia para regularlo y definirlo jurídicamente.

Así pues, el contenido del derecho fundamental, a saber, sus titulares (la definición del "ciudadano" que goza del estatus básico de libertad e igualdad), su objeto (qué regula el derecho fundamental), su contenido en sentido estricto (el haz de facultades o las técnicas de garantía del objeto del derecho) y sus límites (en qué casos, quién y cómo se puede privar de protección iusfundamental a una conducta inicialmente encuadrable en el objeto del derecho) viene definido ya por la Gesamtverfassung y a esa definición está sujeto positivamente el legislador, sea el estatal, sea el territorial, que no puede alterarlo por mucho que pueda contribuir a su delimitación, li-

55 No se nos escapa que tras esta afirmación está la inevitable cuestión del alcance de la actuación de la jurisdicción constitucional en este contexto, pues ella es la llamada a comprobar si la definición legal de la materia competencial (qué sea "aguas" o "pesca") es constitucionalmente conforme. Una vez más nos topamos con el debate sobre la naturaleza "política" de la definición de las materias, o la "jurisdiccional", y el papel que en todo ello deben jugar los Tribunales Constitucionales. 
mitación o promoción (esta es la función de la cláusula de contenido esencial del art. $53.1 \mathrm{CE})^{56}$.

\section{B) LOS DERECHOS FUNDAMENTALES NO SON "MATERIAS" COMPETENCIALES NI OBJETO DE REPARTO COMPETENCIAL}

Cuando Cabellos Espierrez se refiere, reflexionando sobre los giros jurisprudenciales del TC relativos al art. 149.1.1 CE, a la posible y autonómica "diversidad parcial en el contenido de derechos y deberes (allá donde la Constitución no haya dispuesto de inicio la exclusividad de la competencia estatal, naturalmente)", incurre a nuestro modo de ver en un contrasentido desde la perspectiva de la teoría general de los derechos fundamentales ${ }^{57}$. No es posible que haya diversidad de "contenidos" de un derecho fundamental según el territorio en el que se aplique. Semejante situación sería contraria a su propia condición de derechos fundamentales.

El contenido constitucional de un derecho fundamental es uno, el fijado en abstracto en la Constitución. Si no fuese así, no sólo se relativizaría el contenido normativo de la propia Constitución, su supremacía normativa misma, sino que, además, se negaría la condición de fundamentales a los derechos cuyo contenido variaría según el territorio. Los derechos así habrían perdido su carácter de indisponibles en la medida en que lo que sean queda al albur del sujeto creador de la ley que tenga atribuida según el caso la competencia sobre el derecho fundamental, convertido de este modo en materia competencial.

Si es ésta la perspectiva que se adopta, no extraña que el debate en torno al art. 149.1.1 CE haya girado justamente sobre el alcance de una competencia, que aparece como concurrente, del Estado central y las CCAA para regular el contenido del derecho fundamental. Sin embargo la tesis aquí sostenida es muy distinta.

Los derechos fundamentales forman parte de la Gesamtverfassung en la que se constituye el Estado compuesto, se reconduce a unidad y se efectúa el reparto de poderes entre los territorios y el centro. En ella, en esa Constitución global se asegura la horizontalidad del reparto y la co-ordenación entre poderes regionales y centrales, garantizando que entre ellos no exista una relación de subordinación.

La función que le compete a los derechos fundamentales en esa Gesamtverfassung es poner a disposición de los individuos espacios de autodeterminación de la conducta, indisponibles a los poderes públicos, y en parti-

56 Sobre todos estos extremos consúltese el ya citado BASTIDA, VILLAVERDE, REQUEJO, PRESNO, ALÁEZ, FERNÁDEZ, Teoría general, Cap. 7; pero también y manteniendo tesis discrepantes con lo sostenido en ese capítulo, Javier JIMÉNEZ CAMPO, Derechos fundamentales. Concepto y garantías, Trotta, Madrid, 1999. Véase a título general los trabajos publicados en el libro colectivo dirigido por BENDA Y LÓPEZ PINA, La garantía constitucional de los derechos fundamentales: Alemania, España, Francia e Italia, Civitas, Madrid, 1991.

57 Miguel Ángel CABELLOS ESPIERREZ, Distribución competencial..., ob.cit., p. 25. 
cular al poder legislativo. Como tales, pues, los derechos fundamentales se superponen a la legislación, sea la estatal central o la territorial. Su indisponibilidad legal impide, en principio, que una y otra legislación puedan hacer de los derechos objeto de su función creadora de normas. En consecuencia, los derechos no pueden ser objeto de reparto competencial.

Cosa distinta es, de un lado, el reparto que hace la Gesamtverfassung de las habilitaciones para que la ley pueda disponer de algún aspecto del contenido (en sentido general) de los derechos fundamentales (reservas de limitación y de desarrollo de los derechos fundamentales). De otro lado, lo que resulta ajeno al reparto competencial es el derecho fundamental, pero no su régimen jurídico, algo de lo que hablaremos más abajo.

Los derechos fundamentales no se reparten, ni pueden ser objeto de reparto competencial. No forman parte de la norma constitutiva ni del Estado central ni de los entes territoriales. De ellos sólo dispone el constituyente de la Constitución global del Estado compuesto.

Pero la forma de Estado incide en los derechos fundamentales toda vez que éstos pueden ser objeto de una actividad normadora a cargo de los poderes constituidos. Saber quién es el competente para efectuar dicha formación depende en los Estado compuestos del diseño constitucional del orden de reparto de competencias. Los derechos fundamentales, desde luego, no son ajenos al Estado compuesto porque las reglas del reparto de competencias y su sistema de fuentes determinan quién, cómo y de qué forma se puede hacer uso de las mencionadas habilitaciones constitucionales para regular alguno de sus extremos.

Sin embargo, que esto sea así, que los derechos fundamentales puedan ser objeto de una regulación legal y que para saber a quien le compete hacerla haya que acudir al reparto competencial y a su sistema de fuentes, no significa en modo alguno que los derechos fundamentales son el objeto de esas normas, su materia.

Si el contenido de los derechos, lo que sean y cómo lo son en el ordenamiento, ya está definido en la Constitución global, y vincula positivamente a todos los poderes públicos, estatales o territoriales, el objeto de las normas que los regulen no pueden ser los derechos mismos, su contenido constitucional, porque perderían su condición de indisponibles y, en consecuencia, su calidad misma de fundamentales ${ }^{58}$. El objeto de esa regulación es el modo en

58 Es obvio que esta tesis es frontalmente contraria a propuestas como la formulada por Erhard DENNINGER a mediados de los años ochenta del siglo pasado y que considera a los derechos como normas abiertas cuyo contenido a partir de un mínimo constitucional es definido por la labor del legislador que lo irá integrando y componiendo. Pese a la falta de continuidad de esta doctrina en Alemania, parece haber tenido un remedo en la jurisprudencia del TC de los denominados "derechos fundamentales de contenido adicional" (libertad sindical fundamentalmente) DENNINGER, Verfassungsrechtliche Schlüsselbegriffe, en "festschrift für R. Wassermann", Luchterhand, Neuwid/Darmstadt, 1985, p. 279 y ss. Y el artículo de Jesús GARCÍA TORRES, Reflexiones sobre la eficacia vinculante de los derechos fundamentales, Poder Judicial, núm. 10, 1988, p. 11 y ss., que recogió e hizo suyas las tesis del profesor alemán. Una crítica a la teoría de los de- 
que los derechos fundamentales existen en los diversos sectores sociales, en fin, su régimen jurídico en los distintos ámbitos de la realidad.

C) DeReCho Fundamental Y RÉGIMEN JURÍDiCO DEL DERECHO FUNDAMENTAL.

LA DISTINCIÓN ENTRE EL DERECHO FUNDAMENTAL Y LA REALIDAD SOBRE LA QUE SE PROYECTA COMO CRITERIO DE REPARTO COMPETENCIAL

Pues bien, los derechos fundamentales guardan relación estrecha con la organización territorial del Estado porque su objeto se proyecta sobre la realidad. Y esa realidad en términos competenciales se encuadra siempre en una "materia".

El Título VIII de la CE se encuentra con el Título I en la realidad. Esa realidad para la forma de Estado es jurídicamente relevante en cuanto "materia" objeto del orden constitucional de reparto de competencias. Sucede entonces, que cuando el bloque constitucional fija quién es el competente para regular cierta materia ofrece también otra capital información al sistema jurídico y sus operadores. Mediante el reparto competencial también se identifica al legislador de los derechos fundamentales y en consecuencia quién establece el modo de existencia de los derechos en las "materias".

El Estado central, pues, no puede atribuirse una competencia universal sobre los derechos fundamentales. Ello por muchas y muy buenas razones que ya se han dado aquí. Pero sobre todo porque la competencia para establecer el régimen jurídico del derecho fundamental en cuestión no la atribuye el propio derecho fundamental, sino el sistema de reparto constitucional de competencias entre Estado y, en nuestro caso, CCAA.

La CE no contiene norma implícita alguna que atribuya al Estado central esa competencia exclusiva sobre derechos, ni dicha competencia está en el art. 149.1.1 CE. Este precepto no es un remedo del art. 14.1 de la Constitución española de $1931^{59}$. Pero tampoco hay una norma constitucional que convierta a los derechos fundamentales en una materia competencial autonómica.

El derecho fundamental está inevitablemente ligado tanto al sector de la realidad o al ámbito jurídico sobre el que se proyecta cuanto, en palabras de la STC 173/1998 (FJ 6), al régimen jurídico de esos sectores o ámbitos que nacen de su ejercicio (que en el caso de esa Sentencia era evidente, pues una

rechos fuente puede verse en el citado BASTIDA, VILLAVERDE, REQUEJO, PRESNO, ALÁEZ, FERNÁDEZ, Teoría general, p. 134 y ss.

59 Art. 14.1 Constitución española de 1931: «Son de la exclusiva competencia del Estado español la legislación y la ejecución directa en las materias siguientes: 1 . Adquisición y pérdida de la nacionalidad y regulación de los derechos y deberes constitucionales". Sobre este precepto véase PEMÁN GAVÍN, Igualdad de los ciudadanos y autonomias territoriales, PUUZ/Civitas, Madrid, 1992, p. 229-230; TUDELA ARANDA, Derechos constitucionales y autonomía política, IVAP/Civitas, Madrid, 1994, p. 42 y ss. 
cosa es el derecho fundamental de asociación y otra, conexa pero distinta, las asociaciones) $)^{60}$.

Esto es, y traída la cuestión al terreno del reparto constitucional de competencias, un derecho fundamental está anudado a "las actividades, funciones e institutos jurídicos relativos a un sector de la vida social" (STC 123/1984, FJ 2) sobre los que se proyecta el ejercicio del derecho fundamental en cuestión, bien porque su propio contenido, objeto y límites constitucionalmente definidos constituyen por sí mismos un sector de la vida social, e incluso generan ámbitos jurídicos propios con su ejercicio (repárese en el caso del derecho a la tutela judicial y demás conexos — art. $24 \mathrm{CE}$ - , el derecho a la educación —art. $27 \mathrm{CE}$ - , la libertad sindical —art. $28 \mathrm{CE}$ - , el derecho de negocaciación colectiva — art. $37 \mathrm{CE}$ - , derecho de asociación y régimen de las asociaciones - art. $22 \mathrm{CE}$ - , libertad de empresa y derecho mercantil y mercado libre — art. $38 \mathrm{CE}$-; derecho a contraer matrimonio — art. $32 \mathrm{CE}$ - , derecho de propiedad - art. $33 \mathrm{CE}-$ ), o bien porque su ejercicio puede llevarse a cabo en ámbitos muy diversos cuyo régimen juridico se ve afectado por esta circunstancia (éste pudiere ser el caso del derecho a la vida —art. $15 \mathrm{CE}$ - , libertad religiosa e ideológica —art. 16-, libertad de expresión e información —art. 20.1 a) y d) CE—, derecho a la intimidad — art. 18.1 CE-, derecho de reunión y manifestación - art. $21 \mathrm{CE}$ ).

Salvo en el primero de los dos casos expuestos, la Constitución no ha integrado en el derecho fundamental en cuestión esos sectores de la vida social o ámbitos jurídicos como si fueren elementos de su definición constitucional, no constituyendo contenido, objeto o límite del derecho fundamental, y en esa medida su regulación no sería "desarrollo" del derecho (art. 81.1 CE), sino regulación de su ejercicio (art. 53.1 CE), donde Estado y Comunidades Autónomas pueden dictar normas legales sobre derechos fundamentales en función de sus respectivos títulos competenciales (STC 37/1981).

Sin embargo, cuando la materia objeto de una reserva de ley no es ya el derecho fundamental, en sí mismo considerado, sino el sector de la vida social o el ámbito normativo sobre el que se proyecta ese derecho fundamental, en fin, su régimen jurídico, no debe soslayarse que la norma resultante del ejercicio de la reserva estará constitucionalmente condicionada por los títulos competenciales existentes respecto de las materias, éstas sí competenciales, en las que aquel sector de la vida social o ámbito normativo deban subsumirse. Razón por la que, no siendo una reserva de ley por definición una norma atributiva de competencias en este sentido preciso de técnica de reparto en el marco de la organización territorial del Estado, en ese caso la identificación del destinatorio de la reserva de ley será quien resulte del reparto competencial que viene a complementar dicha reserva; éste es el caso, a nuestro juicio, del art. 53.1 CE.

60 Sobre la debida distinción entre el derecho fundamental y el ámbito de la realidad o sector jurídico sobre el que se proyecta véase BASTIDA, VILLAVERDE, REQUEJO, PRESNO, ALÁEZ, FERNÁDEZ, Teoría general, p. 117 y ss. 
Los derechos fundamentales se ligan con las materias competenciales y su reparto (al margen de casos específicos como los apartados 27 y 30 del art. 149.1 CE), cuando la regulación de su ejercicio se debe cohonestar con los títulos competenciales del Estado y las CC.AA. al concurrir aquella regulación y estos títulos en un mismo lugar: el sector de la vida social o el ámbito normativo en el que se ejerce el derecho fundamental en cuestión.

A la Comunidad Autónoma, como al legislador ordinario estatal, le está vedado regular aquellos elementos esenciales que componen constitucionalmente el derecho fundamental y que únicamente el legislador orgánico está llamado a precisar, aun cuando esa posible incidencia pueda resultar del legítimo ejercicio de una competencia propia. Pero las potestades que puedan tenerse conferidas sobre el sector real o jurídico sobre el que se proyecte el derecho fundamental o resulte de su ejercicio, en tanto sector de la vida social o ámbito normativo y no elemento esencial del derecho fundamental, se repartirán atendiendo a la distribución constitucional de títulos competenciales. Reparto en el que deberán compatibilizarse los títulos que sobre ese sector ligado a un derecho fundamental correspondan al Estado y a las Comunidades Autónomas (STC 37/1981 FJ 2), y que estará en función de la materias competenciales en las que quepa subsumir las distintas facetas del citado sector de la vida social o ámbito normativo en el que se desenvuelve por fuerza todo derecho fundamental.

Pero el derecho fundamental no puede, ni debe, absorber hasta su total agotamiento ese sector de la vida social sobre el que se proyecta, ya que, de ser así, se daría lugar a una doble y perversa consecuencia. De un lado, se extendería insoportablemente el ámbito reservado a la Ley Orgánica (STC 5/1981 FJ 21 A, 76/1983 FJ 2, 127/1994 FJ 3). Y de otro, se reservaría también en exclusiva al Estado la regulación del ejercicio de los derechos fundamentales, desconociendo que el art. 53.1 CE sólo efectúa una reserva a la Ley, y esta es una forma de la que pueden disponer tanto el Estado como las CC.AA. (STC 37/1981, FJ 2).

Por lo demás, se eludiría, el hecho mismo de que los derechos fundamentales se ejercen sobre sectores vitales o ámbitos jurídicos ligados, y en ocasiones plenamente identificables, con materias competenciales que la propia Constitución ha sometido a reparto entre los distintos entes territoriales que componen el Estado en su conjunto.

En el caso español, la Constitución ha querido, con el infranqueable límite de la Ley Orgánica de desarrollo del derecho fundamental en cuestión, que tanto el Estado como las Comunidades Autónomas puedan regular mediante Ley el ejercicio de los derechos fundamentales en atención a lo que resulte de sus respectivos títulos competenciales. Nada impediría, incluso, aquella colaboración normativa entre formas jurídicas que, por exigencias prácticas, puedan establecer regulaciones infralegales de carácter secundario y auxiliares de la regulación legal del ejercicio de aquel derecho fundamental tanto por uno como por otro ente, siempre con sujeción, claro está, a la ley estatal o autonómica pertinente (SSTC 83/1984, FJ 4, 137/1986 FJ 3, 254/1994, FJ 5). 
D) Competencias legislativas y Derechos Fundamentales: ART. 53, 81 Y 149.1.1 CE

A nuestro juicio el art. 149.1.1 CE no ofrece al Estado central una competencia legislativa universal sobre los derechos, como si se tratare de una reserva general de desarrollo y regulación del ejercicio de los derechos fundamentales a su favor.

De un lado, y a la vista de lo establecido en el art. 53.1 y $81.1 \mathrm{CE}$, la CE no atribuye al Estado central una competencial general en el art. 149.1.1 para la regulación de los derechos fundamentales. El legislador orgánico, cuando desarrolla derechos fundamentales, al igual que cuando reforma la Constitución, no lo es del Estado central, sino de la Gesamtverfassung. La Ley orgánica es una variante de la forma de ley que pertenece al ordenamiento global con vigencia en todo el territorio del país y única competente para desarrollar el contenido de un derecho fundamental.

La ley orgánica del art. 81.1 CE, en tanto puede delimitar el derecho fundamental y concretar de forma temporal (pues otra ley orgánica puede modificarla) y general (por cuanto su delimitación del derecho fundamental se impone a todos los sujetos del ordenamiento) cuál sea su contenido, cierra una apertura constitucional integrando de este modo un bloque de la constitucionalidad, ya que, en tanto no sea declarada inconstitucional (pues hasta para el legislador orgánico el derecho fundamental es indisponible), lo que sea el derecho fundamental vendrá concretado por la ley orgánica que lo desarrolle $^{61}$. Es por esto que, a nuestro juicio, el legislador orgánico, al tener atribuída esa función de cierre constitucional, actúa como órgano de la Gesamtverfassung imponiéndose al resto. El art. 81.1 no atribuye competencias porque su "materia" no es competencial, al ser su objeto los derechos fundamentales. Pero sin duda habilita al legislador estatal, a quien le atribuye ahora la función de ser legislador del Estado total para cerrar la apertura constitucional relativa a derechos fundamentales.

La cuestión es muy otra cuando se trata de regular el ejercicio de los derechos. El art. 53.1 CE es una norma que regula una habilitación tanto para el Estado, esta vez sí, central, como para las CCAA. La ley estatal central y la ley autonómica son normas idóneas para regular el ejercicio de los derechos fundamentales (STC 37/1981 FJ 2). Como hemos tenido ocasión de afirmar en otro lugar ${ }^{62}$, el art. 53.1 CE no atribuye al Estado central una competencia genérica y universal para regular el ejercicio de los derechos fundamentales, desligada de las materias competenciales del Estado central, "que incluso se sobreponga a las regulaciones sectoriales del ejercicio del

61 Este argumento se desarrolla con mayor detalle en la p. 164 y ss. del libro BASTIDA, VILLAVERDE, REQUEJO, PRESNO, ALÁEZ, FERNÁDEZ, Teoría general de los derechos fundamentales, ob.cit.

62 Véase BASTIDA, VILLAVERDE, REQUEJO, PRESNO, ALÁEZ, FERNÁDEZ, Teoría general de los derechos fundamentales, ob.cit., p. 170. 
derecho en cuestión efectuadas por las Comunidades Autónomas. Nada ha dicho expresamente sobre este extremo el TC y las veces que se ha pronunciado ha sido para vincular la ley estatal o al desarrollo de los derechos del art. 81.1 CE (STC 173/1998) o al art. 149.1.1 CE (SSTC 37/1981, 290/2000). A nuestro juicio, y dado que el art. 149.3 no atribuye ninguna competencia universal al Estado ni siquiera para crear normas supletorias (SSTC 15/1989, 118/1996), éste carece de esa competencia genérica a salvo lo dispuesto en el art. 141.1.1 CE. Como dice la citada STC 37/1981, la ley del art. 53.1 CE sólo será ley de Cortes Generales cuando con esa regulación genérica del ejercicio de los derechos el Estado pretenda establecer las condiciones básicas que garanticen la igualdad de todos los españoles en su ejercicio. Para el resto de los casos, la regulación del ejercicio de un derecho fundamental será competencia de aquel que tenga atribuida la de la materia en la que se encuadra dicha regulación. Así lo expresa la STC 173/1998 (FJ 7):

\begin{abstract}
"Pues bien, uno de los criterios fundamentales que, junto a los ya mencionados, ha orientado la realización de esta tarea de definición sistemática ha sido la de reservar al Estado ex art. 81.1 C.E. la regulación de los aspectos esenciales, el desarrollo directo del derecho fundamental considerado en abstracto o "en cuanto tal", en tanto que se atribuye la regulación de la "materia" sobre la que se proyecta el derecho al legislador ordinario, estatal o autonómico, con competencias sectoriales sobre la misma (SSTC 127/1994, 61/1997 y, en relación concretamente con el derecho de asociación, SSTC 67/1985 y 157/1992)".
\end{abstract}

Si esto es así, ni el legislador estatal ni el autonómico están apoderados para introducir diversidad alguna en el contenido del derecho fundamental en cuestión; ni siquiera, desde luego, para contrariar lo dispuesto en la ley orgánica que lo desarrolle de existir ésta. El art. 53.1 CE, como ya se ha dicho, sólo habilita al legislador estatal y autonómico para regular el ejercicio de los derechos fundamentales fijando sus condiciones de modo, tiempo y forma (STC 292/2000), pero no pudiendo concretar extremo alguno relativo a sus titulares, a su objeto, a su contenido en sentido estricto y a sus límites.

\title{
IV. ¿PUEDEN LOS ESTATUTOS DE AUTONOMÍA TENER SU PROPIA DECLARACIÓN DE DERECHOS?
}

Sólo de forma muy tangencial se planteó esta cuestión con ocasión de la impugnación de la Ley Orgánica 11/1980, de 1 de diciembre, relativa a los supuestos previstos en el art. 55.2 de la Constitución. Como bien se sabe, dicha impugnación de la Ley estatal provocó un debate sobre la legitimación del Parlamento vasco para plantear el recurso de inconstitucionalidad resuelto en 
la STC 25/1981. El argumento del recurrente se cifraba en lo dispuesto en el art. 9.2 a) y c) del EA del País Vasco según el cual los poderes públicos vascos, "velarán y garantizarán —en el ámbito de sus competencias- el adecuado ejercicio de los derechos y deberes fundamentales de los ciudadanos" y "adoptarán aquellas medidas dirigidas a promover las condiciones y a remover los obstáculos para que la libertad y la igualdad del individuo y de los grupos en que se integra sean efectivas y reales".

La mencionada Sentencia sostuvo lo siguiente (FJ 5):

"El art. 9 del Estatuto de Autonomía para el País Vasco no contiene, pues, una norma atributiva de competencia, es decir, una norma que habilite a los poderes públicos vascos para actuar en una determinada materia en la que carecerían de atribuciones de no existir aquélla. Antes bien, lo que hace este precepto es concretar con respecto a los poderes públicos vascos unas obligaciones impuestas por la Constitución a todos los poderes públicos y que éstos, sin excepción, deben cumplir en el ámbito de sus competencias respectivas. En otras palabras, el art. 9 del Estatuto de Autonomía no atribuye una específica competencia a los poderes públicos vascos, sino que se limita a subrayar una obligación que deben observar todos los poderes públicos, centrales y autonómicos, en el ejercicio de las atribuciones que a cada uno de ellos reconoce el ordenamiento jurídico. No podría ser de otra manera, si se tiene en cuenta que con arreglo a la Constitución "la regulación de las condiciones básicas que garanticen la igualdad de todos los españoles en el ejercicio de los derechos y en el cumplimiento de los deberes constitucionales" es materia de la exclusiva competencia del Estado (artículo 149.1.1), y que "todos los españoles tienen los mismos derechos y obligaciones en cualquier parte del territorio del Estado" (art. 139.1).

"Que esto es así lo demuestra el propio art. 9 del Estatuto de Autonomía para el País Vasco, que, al aludir a los deberes reseñados de los poderes públicos vascos, precisa que éstos se desarrollarán "en el ámbito de su competencia". Se pone con ello de relieve que el precepto no puede ser entendido autónomamente como una norma habilitante de competencia, sino que debe ser puesto en relación con los restantes preceptos del Estatuto que determinan las correspondientes competencias.

"Por estas razones, lo dispuesto por el art. 9 del Estatuto de Autonomía no permite sostener que el recurrente está investido de legitimación en el presente caso. "En la línea de las anteriores consideraciones, es preciso tener en cuenta que la Constitución reserva a las Cortes Generales todo cuanto se refiere al desarrollo de los derechos fundamentales y de las libertades públicas, que constituyen el fundamento mismo del orden político-jurídico del Estado en su conjunto, como les reserva también su posible suspensión, sobre la base del art. 55.2, aplicación del cual es la Ley Orgánica 11/1980 recurrida”.

Claro está que el TC se limitó en este caso a resolver una cuestión de legitimación procesal para impugnar una ley estatal haciendo uso del recurso de inconstitucionalidad. Pero lo cierto es que del tenor del precepto del Estatuto de Autonomía vasco y de la respuesta del TC es difícil sustraerse a la pregunta que encabeza este epígrafe. 
¿Es una pregunta de fácil respuesta? No. Pero esta tajante negación requiere de alguna explicación ${ }^{63}$. Los Estatutos de Autonomía no son normas constitucionales, son leyes del Estado. En esa medida, los derechos que en ellas se enumeren como "derechos fundamentales" no gozan de la indisponibilidad para el legislador que hace justamente de un derecho un derecho fundamental. A todos los efectos, serían derechos legales establecidos en una ley orgánica reforzada, pero susceptible de modificación por el propio legislador.

Es más, de hacerlo ni siquiera sería materia estatutaria y no se beneficiaría esa declaración de derechos de la rigidez que el art. 147 prevé para la reforma de los Estatutos de Autonomía. En consecuencia, cualquier otra norma con rango de ley, sin necesidad de que sea orgánica, podría modificar lo así dispuesto en un Estatuto.

En suma, si el legislador orgánico u ordinario pueden disponer de la existencia de esos derechos, éstos en modo alguno cabe calificarlos de derechos fundamentales.

Cosa bien distinta es que la CCAA puedan establecer en sus Estatutos una declaración de derechos estatutarios (y ese es el caso, por ejemplo, con los derechos políticos aparejados a la condición de ciudadano de la CCAA en cuestión) que vinculen a los poderes públicos de dicha CCAA. No hay norma constitucional que lo impida, pero en ningún caso sería una derclaración de derechos fundamentales.

Cuestión también distinta es si los Estatutos o las normas con rango de ley de la CCAA pueden regular los derechos fundamentales de la CE. En un caso u otro el alcance de esa asunción depende por entero del orden de reparto de competencias entre Estado central y CCAA. Así debe ser, ya que hacerlo en el EA no es más que una forma de atender al mandato del art. 9.2 CE que, en todo caso, no exime a la CCAA de sujetarse fielmente al orden constitucional de competencias, ya que la regulación de los derechos está sometida a estrictas normas de la CE (art. 81.1, 53.1 y 149.1.1 CE). Otro tanto cabe decir de la segunda cuestión, pues la capacidad de las CCAA para regular por ley un derecho fundamental es un asunto que, de nuevo, sólo puede resolverse sabiendo en el marco de qué materia la Comunidad Autónoma quiere regular el

63 Miguel Angel CABELLOS ESPIÉRREZ no le da relevancia a esta cuestión, que a nuestro juicio si la tiene, siquiera porque es éste un rasgo del modelo autonómico (federal) español que lo distingue de los Estado federales como EEUU y la República Federal de Alemania en los que las Constituciones de sus Estados federados contienen declaraciones de derechos (Distribución competencial, ob.cit., p. 13 y ss.). Prueba de la relevancia y complejidad de la cuestión son los trabajos de Luis María DIEZ-PICAZO de título tan expresivo, ¿Pueden los Estatutos de Autonomía declarar derechos, deberes y principios?, Revista Española de Derecho Constitucional, núm. 78, 2006, pp. 63 y ss., con quien se comparten en líneas generales los argumentos, aunque se discrepa del resultado; y la respuesta que a él da Francisco CAAMAÑO DOMíNGUEZ, Sí pueden. (Declaraciones de derechos y Estatutos de Autonomia), Revista Española de Derecho Constitucional, núm. 79, 2007, pp. 33 y ss., con quien se comparte el resultado, pero no en general los argumentos para llegar a él. 
derecho, y si, por lo demás, el tipo de regulación legal (desarrollo, regular el ejercicio, limitar, promover una política de derechos) es de aquellas para las que la Comunidad Autónoma tiene título competencial suficiente ${ }^{64}$.

ABSTRACT. In this work are analized the implications that the state form bears in the regulation of the fundamental rights.

64 RUGGIERI, Neorregionalismo, ob.cit., p. 211 y ss., se acerca a estas cuestiones de un modo sugerente. El autor italiano distingue entre aquellas regulaciones sobre la organización y las funciones de los órganos de la Región que incidan en el disfrute de los derechos, en el marco de las cuales se pueden practicar una política de derechos y además que la regulación de esa organización y su funcionamiento aseguren la participación de los ciudadanos en sus procesos de decisión (caso de los derechos políticos en las CCAA, p. 211 y s). En segundo lugar, la posibilidad de que se erija un doble sistema de tutela de los derechos, el estatal y el autonómico (p. 215). En tercer lugar, y en esto se discrepa del autor, los derechos incorporados a los Estatutos (en este caso de las nuevas regiones italianas tras la reforma constitucional de 2001) son verdaderos derechos fundamentales porque los Estatutos son normas materialmente constitucionales (p. 218). 